\title{
Mitochondrial Affinity of Guanidine-rich Molecular Transporters Built on myo- and scyllo-Inositol Scaffolds: Stereochemistry Dependency
}

\author{
Subhash C. Ghosh, Boram Kim, Jungkyun Im, Woo Sirl Lee, Chang-Nim Im, ${ }^{\dagger}$ Young-Tae Chang, ${ }^{\dagger}$ Wanil Kim, \\ Kyong-Tai Kim, ${ }^{\ddagger}$ and Sung-Kee Chung* \\ Department of Chemistry, Pohang University of Science and Technology, Pohang 790-784, Korea \\ *E-mail: skchung@postech.ac.kr \\ 'Department of Chemistry, National University of Singapore, Singapore 117543, Laboratory of Bioimaging Probe \\ Development, Singapore Bioimaging Consortium, Agency for Science, Technology and Research (A*STAR) Biopolis, \\ Singapore 138667, Singapore \\ ${ }^{\ddagger}$ Department of Life Science, Pohang University of Science and Technology, Pohang 790-784, Korea \\ Received July 6, 2010, Accepted October 4, 2010
}

\begin{abstract}
We prepared several novel molecular transporters built on myo- and scyllo-inositol scaffolds with variations in the number of guanidine residues, linker chain lengths and patterns. Some of these transporters were found to localize in mitochondria, and the mitochondrial affinity seems to be substantially related to the scaffold stereochemistry.
\end{abstract}

Key Words: Blood-brain barrier, Cellular membrane, Drug delivery, Inositol scaffold, Mitochondrial affinity

\section{Introduction}

Efficient drug delivery and good bioavailability at target tissues are important factors in the new drug development, because many drug candidates with promising in vitro activity fail or find only limited applications due to poor absorption, distribution, metabolism or excretion (ADME) profiles. Highly desired are novel molecular transporters that can help a promising drug candidate to be taken up by cells and delivered to the desired organelles or tissues. In this connection, substantial research efforts have been extended to several classes of cellpenetrating peptides (CPPs) such as HIV-1 Tat protein. CPPs and related peptides have been extensively studied for their potential utilities as delivery vehicles in order to enhance pharmacological properties of drugs having poor bioavailability, including small molecules, proteins, genes, etc. ${ }^{1-5}$ However, the CPPs have a number of limitations, including instability toward endogenous peptidases, immunogenic liability, inter-tissue permeation despite their interesting in vitro characteristics. In efforts to improve upon these limitations, several different types of synthetic molecular transporters (MTs), e.g. peptoids, ${ }^{6}$ oligocarbamates, ${ }^{7} \beta$-peptides, ${ }^{8}$ peptide nucleic acids, ${ }^{9}$ and others ${ }^{10-13}$ have been investigated.

Recently we have explored novel classes of synthetic molecular transporters, in which multiple units of the guanidine functionality are attached through linear or branched chain carboxylate linkers to various scaffolds such as inositol dimers, sorbitol, lactose, and sucrose. ${ }^{14-17}$ Many of these MTs exhibited good cellular uptake properties, and moreover diverse intracellular organellar and tissue selectivity was observed somewhat unexpectedly. For example, several G8 (containing eight guanidine residues) molecular transporters based on the sorbitol scaffold and branched chain linkers showed intracellular selectivity, namely a good affinity toward mitochondria in HeLa as well as $\mathrm{CD} 34^{+}$stem cell-like KG1a leukaemia cells. ${ }^{15}$ This observa- tion was deemed highly interesting because of their potential as mitochondria selective delivery vectors, especially in view of a dearth of viable mitochondrial transporters. ${ }^{18-20}$ It is now recognized that mitochondria play essential roles in many intractable neural and neuromuscular diseases such as familial amyotrophic lateral sclerosis (ALS), Alzheimer's disease, and Huntington's disease, as well as in apoptosis and aging. ${ }^{21-25}$ In addition, the sorbitol-based G8 transporters also displayed more affinity for heart muscle and brain sections in mice than any other tissues examined. Studies with lactose-based G7 molecular transporters ${ }^{16}$ and sucrose-based G7 molecular transport$\mathrm{ers}^{17}$ showed that the mitochondrial affinity and the organellar distribution pattern in general appear to be related to the charge (number of guanidine residues), the nature of scaffold, flexibility and lipophilicity of the linker chains, and even the cargo attached. In order to better understand the structure-property relationships with a particular focus on the mitochondrial affinity, we have now studied the effect of the scaffold stereochemistry in a series of G8 molecular transporters built on two inositol stereoisomers, namely myo- and scyllo-inositols.

\section{Experimental}

\section{Synthesis.}

General methods: All non-hydrolytic reactions were carried out in oven-dried glassware under an inert atmosphere of dry argon or nitrogen. All commercial chemicals were used as received except for solvents, which were purified and dried by standard methods prior to use. Analytical TLC was performed on a Merck 60 F254 silica gel plate $(0.25 \mathrm{~mm}$ thickness $)$ and analytical reverse-phase TLC on a Merck RP-8 F254s, and visualization was done with UV light ( $254 \mathrm{~nm}$ and $365 \mathrm{~nm}$ ), and/or by spraying with a $5 \%$ solution of phosphomolybdic acid or ninhydrin, followed by charring with a heat gun. Column chromatography was performed on Merck 60 silica gel (70 - 230 or 
230 - 400 mesh), and MPLC was performed on Fluka 100 C8reversed phase silica gel. Melting points were determined on a Thomas-Hoover MP apparatus and uncorrected. NMR spectra were recorded on a Bruker DPX $300\left({ }^{1} \mathrm{H}-\mathrm{NMR}\right.$ at $300 \mathrm{MHz}$; ${ }^{13} \mathrm{C}-\mathrm{NMR}$ at $\left.75 \mathrm{MHz}\right)$ and Bruker DRX $500\left({ }^{1} \mathrm{H}-\mathrm{NMR}\right.$ at 500 $\mathrm{MHz} ;{ }^{13} \mathrm{C}-\mathrm{NMR}$ at $125 \mathrm{MHz}$ ) spectrometers. Tetramethysilane was used as reference, and the chemical shift were reported in $\delta$ ppm and the coupling constant in Hz. Analytical HPLC was performed on Agilent 1100-HPLC Chemstation with an analytical column ZORBAX SB-C8 $(5 \mu \mathrm{m}, 4.6 \mathrm{~mm}$ ID $\times 25 \mathrm{~cm})$. Low resolution mass spectra were determined on a Micromass PLATFORM 11 (EI and FAB). High resolution mass spectra were done on a JMS-700 at Korea Basic Science Institute (Daegu), and MALDI-TOF mass spectra on a Voyager-DE STR system at POSTECH. The standard extractive work-up procedure consisted of pouring into a large amount of water, extracting thoroughly with the organic solvent indicated, washing the combined extract successively with water and brine, drying the extract over anhydrous $\mathrm{Na}_{2} \mathrm{SO}_{4}$ or $\mathrm{MgSO}_{4}$, and evaporating the solvent.

DL-4-O-Benzoyl-1-O-(6- $\mathrm{N}$-Cbz-aminohexanoyl)-2,3:5,6di-O-isopropylidene-myo-inositol (7): A solution of compound 6 $^{26}$ (350 mg, $0.960 \mathrm{mmol}$ ), 6- $N$-Cbz-amino hexanoic acid (290 $\mathrm{mg}, 1.15 \mathrm{mmol}$ ), EDC (221 mg, $1.15 \mathrm{mmol}$ ) and DMAP (35 mg, $0.288 \mathrm{mmol})$ in DMF $(5 \mathrm{~mL})$ was stirred overnight at rt under $\mathrm{N}_{2}$. The reaction mixture was diluted with EtOAc, washed with $\mathrm{H}_{2} \mathrm{O}, \mathrm{NaHCO}_{3}$ and brine. Organic phase was dried and concentrated to give the crude product, which was purified by column chromatography (EtOAc: $n$-Hexane $=1: 2$ ) to afford compound $7(505 \mathrm{mg}, 86 \%)$ as a white solid. $\mathrm{mp} 160-162{ }^{\circ} \mathrm{C} ; R_{f} 0.29$ $($ EtOAc: $n$-Hexane $=1: 2) ;{ }^{1} \mathrm{H}$ NMR $\left(\mathrm{CDCl}_{3}\right) \delta 1.32,1.43,1.48$, $1.64\left(4 \mathrm{~s}\right.$, each $\left.3 \mathrm{H}, 2-\mathrm{CMe}_{2}\right), 1.37-1.58(\mathrm{~m}, 6 \mathrm{H}), 2.47(\mathrm{t}, J=7.2$ $\mathrm{Hz}, 2 \mathrm{H}$ ), 3.20-3.22 (m, 2H), 3.65 (dd, $J=11.0,9.3 \mathrm{~Hz}, 1 \mathrm{H}, \mathrm{H}-6)$, 4.23 (t, $J=10.0 \mathrm{~Hz}, 1 \mathrm{H}, \mathrm{H}-5), 4.33$ (dd, $J=6.7 \mathrm{z}, 4.9 \mathrm{~Hz}, 1 \mathrm{H}$, H-3), 4.67 (t, J=4.5 Hz, 1H, H-2), 4.79 (br. s, 1H, -NH-), 5.10 (s, $\left.2 \mathrm{H},-\mathrm{CH}_{2}-\mathrm{Ph}\right), 5.18$ (dd, $\left.J=10.5,4.2 \mathrm{~Hz}, 1 \mathrm{H}, \mathrm{H}-1\right), 5.55$ (dd, $J=11.0,6.8 \mathrm{~Hz}, 1 \mathrm{H}, \mathrm{H}-4), 7.32-8.10$ (m, 10H, $2 \mathrm{Ph}) ;{ }^{13} \mathrm{C} \mathrm{NMR}$ $\left(\mathrm{CDCl}_{3}\right): 24.4,25.9,26.8,26.9,27.7,29.5,33.9,40.8,66.6$, 70.4, 74.6, 74.9, 75.2, 76.5, 79.5, 110.7, 113.0, 128.1, 128.2, 128.3, 128.5, 129.7, 130.0, 133.2, 136.7, 156.4, 165.4, 173.1; HRMS (FAB): $m / z$ calcd for $\mathrm{C}_{33} \mathrm{H}_{42} \mathrm{NO}_{10}: 612.2806$; found $612.2809[\mathrm{M}+\mathrm{H}]^{+}$.

DL-4-O-Benzoyl-1-O-(6- $\mathrm{N}$-Cbz-aminohexanoyl)-myo-inositol (8): To a solution of compound $7(256 \mathrm{mg}, 0.418 \mathrm{mmol})$ in $\mathrm{CH}_{2} \mathrm{Cl}_{2}: \mathrm{MeOH}(1: 5,3 \mathrm{~mL})$ was added gaseous $\mathrm{HCl}$ saturated ethyl acetate, and stirring was continued at $\mathrm{rt}$ for $30 \mathrm{~min}$. The reaction mixture was concentrated and washed with ether to give the crude product, which was further purified by flash column chromatography to afford the compound 8 (202 mg, $91 \%)$ as a white sticky solid. $R_{f} 0.47\left(\mathrm{CH}_{2} \mathrm{Cl}_{2}: \mathrm{MeOH}=9: 1\right)$; ${ }^{1} \mathrm{H}$ NMR $\left(\mathrm{CD}_{3} \mathrm{OD}\right) \delta 1.35-1.43(\mathrm{~m}, 2 \mathrm{H}), 1.50-1.56(\mathrm{~m}, 2 \mathrm{H})$, $1.66-1.72(\mathrm{~m}, 2 \mathrm{H}), 2.45(\mathrm{t}, J=7.2 \mathrm{~Hz}, 2 \mathrm{H}), 3.13(\mathrm{t}, J=6.9 \mathrm{~Hz}$, $2 \mathrm{H}), 3.57(\mathrm{t}, J=9.6 \mathrm{~Hz}, 2 \mathrm{H}), 3.78(\mathrm{dd}, J=2.7,10.2 \mathrm{~Hz}, 1 \mathrm{H}), 4.00$ $(\mathrm{t}, J=9.6 \mathrm{~Hz}, 1 \mathrm{H}), 4.14(\mathrm{t}, J=2.6 \mathrm{~Hz}, 1 \mathrm{H}), 4.75(\mathrm{dd}, J=2.7,10.2$ $\mathrm{Hz}, 1 \mathrm{H}), 5.08$ (s, 2H), 5.48 (t, $J=9.8 \mathrm{~Hz}, 1 \mathrm{H}), 7.31-7.37$ (m, 5H, aromatic), $7.45-7.51(\mathrm{~m}, 2 \mathrm{H}$, aromatic), 7.56-7.61 (m, $1 \mathrm{H}$, aromatic), 8.09-8.12 (m, 2H); $\left.{ }^{13} \mathrm{C} \mathrm{NMR} \mathrm{(CD} \mathrm{OD}\right) \delta 25.7,27.4$, 30.7, 35.1, 41.8, 67.5, 71.4, 72.0, 72.1, 74.6, 75.6, 77.0, 128.9, 129.1, 129.5,129.6, 130.9, 132.1, 134.2, 138.6, 159.1, 168.3,
175.2; HRMS (FAB): $m / z$ calcd for $\mathrm{C}_{27} \mathrm{H}_{34} \mathrm{NO}_{10}: 531.2178$; found $531.2183[\mathrm{M}+\mathrm{H}]^{+}$.

A representative procedure for exhaustive acylation - A solution of compounds 8 ( $53 \mathrm{mg}, 0.1 \mathrm{mmol}$ ), 12a (438 mg, 0.6 mmol), EDC (115 mg, $0.6 \mathrm{mmol})$ and DMAP (18 mg, 0.15 $\mathrm{mmol}$ ) in DMF ( $2 \mathrm{~mL}$ ) was stirred at $\mathrm{rt}$ under $\mathrm{N}_{2}$ for $48 \mathrm{~h}$. The reaction mixture was diluted with EtOAc, washed several times with $\mathrm{H}_{2} \mathrm{O}, \mathrm{NaHCO}_{3}$ and brine. The organic phase was dried and concentrated. The crude product was purified by column chromatography on silica gel $\left(\mathrm{CH}_{2} \mathrm{Cl}_{2}: \mathrm{MeOH}=9: 1\right)$ to afford compound $9 \mathbf{a}$ as a sticky solid $(314 \mathrm{mg}, 92 \%)$.

DL-4-O-Benzoyl-1-O-(6- $\mathrm{N}$-Cbz-aminohexanoyl)-2,3,5,6tetra- $\boldsymbol{O}$-[6-[bis-(3- $N, \boldsymbol{N}$ '-di-Boc-guanidino-propyl)-amino]hexanoyl]-myo-inositol (9a): Colorless sticky solid; $R_{f} 0.36$ $\left(\mathrm{CH}_{2} \mathrm{Cl}_{2}: \mathrm{MeOH}=9: 1\right) ;{ }^{1} \mathrm{HNMR}\left(\mathrm{CDCl}_{3}\right) \delta 1.01-1.67(\mathrm{~m}, 190 \mathrm{H})$, 2.06-2.46 (m, 32H), 3.14-3.20 (m, 4H), 3.34-3.48 (m, 16H), 4.20-5.81 (m, 6H), $5.02\left(\mathrm{~s}, 2 \mathrm{H}, \mathrm{CH}_{2} \mathrm{Ph}\right) 7.30-7.45(\mathrm{~m}, 7 \mathrm{H}), 7.56-$ 7.59 (m, 1H), 7.92-7.95 (m, 2H), 8.49 (brs, 8H), 11.49 (brs, 8H); ${ }^{13} \mathrm{C} \mathrm{NMR}\left(\mathrm{CDCl}_{3}\right): 22.8,24.1,24.6,24.8,25.1,25.5,26.2,26.4$, $26.8,27.0,27.3,28.2,28.5,28.7,29.8,31.7,33.8,34.0,34.2$, $38.1,39.0,39.7,40.2,41.0,51.6,51.7,52.5,53.2,53.7,53.9$, $66.6,66.7,68.4,69.5,70.2,70.9,71.1,77.4,79.2,79.6,83.0$, $128.1,128.2,128.7,129.2,130.0,133.6,133.7,136.8,136.9$, 153.2, 153.6, 156.2, 156.6, 163.8, 165.3, 172.4, 172.5, 172.6; MALDI-TOF MS: $m / z$ calcd for $\mathrm{C}_{163} \mathrm{H}_{280} \mathrm{~N}_{29} \mathrm{O}_{46}$ : 3380.0; found: $3380.3[\mathrm{M}+3 \mathrm{H}]^{+}$.

DL-4-O-Benzoyl-1-O-(6- $\mathrm{N}$-Cbz-aminohexanoyl)-2,3,5,6tetra- $O$-[8-[bis-(3- $N, N$ '-di-Boc-guanidino-propyl)-amino]octanoyl]-myo-inositol (9b): was similarly prepared from compound $\mathbf{8}(53 \mathrm{mg}, 0.1 \mathrm{mmol}), \mathbf{1 2 b}(454 \mathrm{mg}, 0.6 \mathrm{mmol})$, EDC (115 $\mathrm{mg}, 0.6 \mathrm{mmol})$ and DMAP (18 $\mathrm{mg}, 0.15 \mathrm{mmol})$ as a colorless sticky solid (331 mg, 95\%): $R_{f} 0.39\left(\mathrm{CH}_{2} \mathrm{Cl}_{2}: \mathrm{MeOH}=9: 1\right) ;{ }^{1} \mathrm{H}$ $\operatorname{NMR}\left(\mathrm{CDCl}_{3}\right) \delta$ 0.97-1.63 (m, 206H), 1.84-2.45 (m, 32H), 3.09$3.19(\mathrm{~m}, 4 \mathrm{H}), 3.35-3.48(\mathrm{~m}, 16 \mathrm{H}), 4.20-5.71(\mathrm{~m}, 6 \mathrm{H}), 5.01(\mathrm{~s}, 2 \mathrm{H}$, $\left.\mathrm{CH}_{2} \mathrm{Ph}\right)$ 7.26-7.28 (m, 5H), 7.29-7.38 (m, 2H), 7.42-7.48 (m, 1H), 7.80-7.89 (m, 2H), 8.45 (brs, 8H), 11.43 (brs, 8H). ${ }^{13} \mathrm{C}$ NMR $\left(\mathrm{CDCl}_{3}\right) \delta 24.9,25.0,25.1,25.3,26.4,26.6,27.6,28.4$, 28.7, 28.9, 29.4, 29.5, 29.7, 30.0, 30.1, 31.8, 34.2, 34.3, 34.4, $39.9,41.2,41.5,51.9,52.8,54.2,66.8,67.0,68.7,69.6,69.7$, $70.4,71.0,71.5,79.6,78.0,83.3,128.4,128.5,128.9,129.1$, $129.5,130.2,133.8,134.0,137.0,137.1,153.4,153.6,156.5$, 156.8, 162.9, 163.9, 165.6, 172.5, 172.7, 172.8, 173.0, 174.4; MALDI-TOF MS: $m / z$ calcd for $\mathrm{C}_{171} \mathrm{H}_{294} \mathrm{~N}_{29} \mathrm{O}_{46}$ : 3490.2 ; found: $3490.4[\mathrm{M}+\mathrm{H}]^{+}$.

A representative procedure for the removal of the $N$-benzyloxycarbonyl (Cbz) group - A mixture of compound 9a (150 $\mathrm{mg}, 0.044 \mathrm{mmol})$ in a mixed solvent of $\mathrm{CH}_{2} \mathrm{Cl}_{2}: \mathrm{MeOH}(1: 9,5$ $\mathrm{mL}$ ) was hydrogenated (40 psi) at rt over $10 \% \mathrm{Pd} / \mathrm{C}(30 \mathrm{mg})$. After $24 \mathrm{~h}$, the catalyst was filtered through a celite bed and the filtrate was evaporated to afford free amine 10a (141 mg, 98\%) as an off-white foamy solid.

DL-4-O-Benzoyl-1- $O$-(6-aminohexanoyl)-2,3,5,6-tetra- $O$ [6-[bis-(3-N,N'-di-Boc-guanidino-propyl)-amino]-hexanoyl]myo-inositol (10a): Off-white foamy solid: ${ }^{1} \mathrm{H} \mathrm{NMR}\left(\mathrm{CD}_{3} \mathrm{OD}\right)$ $\delta 1.22-1.74(\mathrm{~m}, 190 \mathrm{H}), 1.98-2.40(\mathrm{~m}, 32 \mathrm{H}), 2.67-3.82(\mathrm{~m}, 20 \mathrm{H})$, 4.28-5.88 (m, 6H), 7.49-7.53 (m, 2H), 7.64-7.66 (m, 1H), 7.957.99 (m, 2H); MALDI-TOF MS: m/z calcd for $\mathrm{C}_{155} \mathrm{H}_{274} \mathrm{~N}_{29} \mathrm{O}_{44}$ : 3246.0094; found: $3246.0450[\mathrm{M}+3 \mathrm{H}]^{+}$. 
DL-4-O-Benzoyl-1-O-(6-aminohexanoyl)-2,3,5,6-tetra- $O$ [8-[bis-(3- $N, N$ '-di-Boc-guanidino-propyl)-amino]-octanoyl]myo-inositol (10b): 10b was similarly prepared from compound 9b (150 mg, $0.042 \mathrm{mmol}$ ) as an off-white foamy solid (145 mg, 98\%): ${ }^{1} \mathrm{H}$ NMR $\left(\mathrm{CD}_{3} \mathrm{OD}\right) \delta 1.15-1.74(\mathrm{~m}, 206 \mathrm{H}), 2.05-2.40(\mathrm{~m}$, $32 \mathrm{H}), 2.87-3.50(\mathrm{~m}, 20 \mathrm{H}), 4.28-5.88(\mathrm{~m}, 6 \mathrm{H}), 7.50-7.54(\mathrm{~m}, 2 \mathrm{H})$, 7.65-7.67 (m, 1H), 7.96-7.99 (m, 2H); MALDI-TOF MS: $m / z$ calcd for $\mathrm{C}_{163} \mathrm{H}_{291} \mathrm{~N}_{29} \mathrm{O}_{44}$ : 3359.1; found: $3359.5[\mathrm{M}+4 \mathrm{H}]^{+}$.

A representative procedure for the FITC-I attachment - To a solution of $10 a(140 \mathrm{mg}, 0.0432 \mathrm{mmol})$ in a mixed solvent THF: abs. ethanol ( $5 \mathrm{~mL}, 2: 3)$, were added fluorescein-5-isothiocyanate $(20.2 \mathrm{mg}, 0.052 \mathrm{mmol})$ and triethylamine $(18 \mu \mathrm{L}, 0.13$ $\mathrm{mmol})$. The reaction mixture was stirred for $24 \mathrm{~h}$ at $\mathrm{rt}$ in dark, concentrated, diluted with ethyl acetate and washed with water. Organic phase was dried and concentrated. The crude product $(160 \mathrm{mg})$ was used without further purification in the next reaction.

DL-4-O-Benzoyl-1- $O$-[6-( $N$-fluoresceinyl-5-thioureido)hexanoyl]-2,3,5,6-tetra- $O$-[6-[bis-(3- $N$, $N$ '-di-Boc-guanidinopropyl)-amino]-hexanoyl]-myo-inositol (11a): $R_{f} 0.39\left(\mathrm{CH}_{2} \mathrm{Cl}_{2}\right.$ : $\mathrm{MeOH}=9: 1) ;{ }^{1} \mathrm{H} \mathrm{NMR}\left(\mathrm{CDCl}_{3}\right) \delta$ 0.9-1.68 (m, 190H), 2.02-2.48 $(\mathrm{m}, 36 \mathrm{H}), 3.40-3.48(\mathrm{~m}, 16 \mathrm{H}), 4.20-5.81(\mathrm{~m}, 6 \mathrm{H}), 6.48-7.12(\mathrm{~m}$, $6 \mathrm{H}), 7.41-7.94(\mathrm{~m}, 8 \mathrm{H}), 8.50$ (brs, $8 \mathrm{H}), 11.48$ (brs, $8 \mathrm{H})$.

DL-4-O-Benzoyl-1- $O$-[6-( $\mathrm{N}$-fluoresceinyl-5-thioureido)hexanoyl]-2,3,5,6-tetra- $O$-[8-[bis-(3- $N, N$ '-di-Boc-guanidinopropyl)-amino]-octanoyl]-myo-inositol (11b): was similarly prepared from 10b (144 mg, $0.43 \mathrm{mmol})$, FITC-1 (20.2 mg, $0.052 \mathrm{mmol})$ and triethylamine $(18 \mu \mathrm{L}, 0.13 \mathrm{mmol})$ as a greenish yellow sticky solid (162 mg): $R_{f} 0.39\left(\mathrm{CH}_{2} \mathrm{Cl}_{2}: \mathrm{MeOH}=9: 1\right) ;{ }^{1} \mathrm{H}$ $\mathrm{NMR}\left(\mathrm{CDCl}_{3}\right) \delta$ 0.82-1.69 (m, 206H), 2.02-2.63 (m, 36H), 3.40$3.79(\mathrm{~m}, 16 \mathrm{H}), 4.05-5.81(\mathrm{~m}, 6 \mathrm{H}), 6.62-7.94(\mathrm{~m}, 14 \mathrm{H}), 8.50$ (brs, $8 \mathrm{H}), 11.47$ (brs, 8H).

A representative procedure for the removal of the $N$-Boc group - A solution of 11a (160 mg crude) in gaseous $\mathrm{HCl}$ saturated ethyl acetate was stirred at rt for $24 \mathrm{~h}$. The solution was concentrated and repeatedly washed with ethyl acetate and ether, and evaporated to give the crude product, which was purified by MPLC on Fluka $100 \mathrm{C} 8$-reversed phase silica gel $\left(\mathrm{CH}_{3} \mathrm{CN}\right.$ : $\mathrm{H}_{2} \mathrm{O}=1: 1$, containing $0.1 \%$ TFA in both $\mathrm{CH}_{3} \mathrm{CN}$ and $\mathrm{H}_{2} \mathrm{O}$ ). After freeze drying, compound 1a (as HCl-salt) was obtained (40 mg, 40\% over two steps).

DL-4-O-Benzoyl-1-O-[6-( $\mathrm{N}$-fluoresceinyl-5-thioureido)hexanoyl]-2,3,5,6-tetra- $O$-[6-[bis-(3-guanidino-propyl)-aminol- hexanoyl]-myo-inositol-8HCl (1a): Greenish yellow foamy solid; UV $\left(\mathrm{H}_{2} \mathrm{O}\right): \lambda_{\max }(\varepsilon)=493 \mathrm{~nm}\left(32843 \mathrm{~cm}^{-1} \mathrm{M}^{-1}\right) ;{ }^{1} \mathrm{H}$ NMR (CD $\left.{ }_{3} \mathrm{OD}\right) \delta 1.14-1.81(\mathrm{~m}, 46 \mathrm{H}), 2.0-2.60(\mathrm{~m}, 34 \mathrm{H}), 2.98-3.85$ (m, 18H), 4.10-5.82 (m, 6H), 6.65-6.80 (m, 4H), 7.20-8.37 (m, $10 \mathrm{H})$; MALDI-TOF MS: $m / z$ calcd for $\mathrm{C}_{96} \mathrm{H}_{155} \mathrm{~N}_{30} \mathrm{O}_{17} \mathrm{~S}: 2032.2$; found: $2032.2[\mathrm{M}+\mathrm{H}]^{+}$; analytical HPLC: $t_{\mathrm{R}}=2.359 \mathrm{~min}$ (flow rate $1 \mathrm{~mL} / \mathrm{min}$; $\mathrm{UV}: \lambda=220 \mathrm{~nm} ; \mathrm{H}_{2} \mathrm{O}: \mathrm{CH}_{3} \mathrm{CN}=40: 60$ with $0.1 \%$ TFA), purity $>95 \%$.

DL-4-O-Benzoyl-1-O-[6-( $\mathrm{N}$-fluoresceinyl-5-thioureido)hexanoyl]-2,3,5,6-tetra- $O$-[8-[bis-(3-guanidino-propyl)-amino]-octanoyl]-myo-inositol-8HCl (1b): was similarly prepared from $11 b$ (162 mg crude) as a light yellow foamy solid (43 mg, $42 \%$ over two steps): $U V\left(\mathrm{H}_{2} \mathrm{O}\right): \lambda_{\max }(\varepsilon)=496 \mathrm{~nm}\left(36838 \mathrm{~cm}^{-1}\right.$ $\left.\mathrm{M}^{-1}\right) ;{ }^{1} \mathrm{H} \mathrm{NMR}\left(\mathrm{CD}_{3} \mathrm{OD}\right) \delta 1.11-1.75(\mathrm{~m}, 62 \mathrm{H}), 2.02-2.55(\mathrm{~m}$, $34 \mathrm{H}), 2.99-3.65$ (m, 18H), 5.01-5.80 (m, 6H), 6.54-6.70 (m, 4H),
7.17-8.37 (m, 10H); MALDI-TOF MS: $m / z$ calcd for $\mathrm{C}_{104} \mathrm{H}_{170^{-}}$ $\mathrm{N}_{30} \mathrm{O}_{17} \mathrm{~S}: 2143.3$; found: $2143.3[\mathrm{M}]^{+}$; analytical HPLC: $t_{\mathrm{R}}=$ $3.162 \mathrm{~min}$ (flow rate $1 \mathrm{~mL} / \mathrm{min}$; $\mathrm{UV}: \lambda=220 \mathrm{~nm} ; \mathrm{H}_{2} \mathrm{O}: \mathrm{CH}_{3} \mathrm{CN}=$ 60:40 with $0.1 \%$ TFA), purity $>95 \%$.

1-O-Benzoyl-2,3:5,6-di- $O$-isopropylidine-scyllo-inositol (14a) and DL-1-O-Benzoyl-2,3:4,5-di- $O$-isopropylidine-scylloinositol (14b): To a solution of 1-benzoyl-2,3,4,5-tetrabenzylscyllo-inositol (compound 20) ${ }^{27}(9.96 \mathrm{~g}, 35.05 \mathrm{mmol}$ ) and p-TSA (3.33 mg, $17.5 \mathrm{mmol})$ in DMF $(110 \mathrm{~mL})$ at $\mathrm{rt}$, was added dropwise 2-methoxypropene $(33.5 \mathrm{~mL}, 350 \mathrm{mmol})$. After 1day, the reaction mixture was poured into aq. $\mathrm{NaHCO}_{3}$ with vigorous stirring, and extracted with EtOAc. The organic layer was dried, concentrated, diluted with EtOAc $(100 \mathrm{~mL})$, and filtered to give compound $14 \mathrm{a}(2.9 \mathrm{~g}, 22.8 \%)$, and the filtrate was evaporated and chromatographed on silica gel to give compounds $\mathbf{1 4 b}$ $(1.4 \mathrm{~g}, 11.5 \%)$ 14a $: R_{f} 0.25$ (EtOAc: $n$-Hexane $\left.=1: 2\right) ; \mathrm{mp}$ $284-285^{\circ} \mathrm{C} ;{ }^{1} \mathrm{H}$ NMR $\left(\mathrm{CDCl}_{3}\right) \delta 1.44,1.47$ (each s, each $6 \mathrm{H}, 2$ $\mathrm{CMe}_{2}$ ), 2.46 (d, $\left.J=2.7 \mathrm{~Hz}, 1 \mathrm{H}, \mathrm{OH}\right), 3.76$ (app. t, $J=9.3 \mathrm{~Hz}, 2 \mathrm{H}$, H-3 \& H-5), 3.85 (app. t, $J=9.3 \mathrm{~Hz}, 2 \mathrm{H}, \mathrm{H}-2 \& \mathrm{H}-6$ ), 4.13 (dt, $J=2.7,8.9 \mathrm{~Hz}, 1 \mathrm{H}, \mathrm{H}-4), 5.60(\mathrm{t}, J=9.2 \mathrm{~Hz}, 1 \mathrm{H}, \mathrm{H}-1), 7.26-8.10$ $(\mathrm{m}, 5 \mathrm{H}, \mathrm{Ph}) ;{ }^{13} \mathrm{C} \mathrm{NMR}\left(\mathrm{CDCl}_{3}\right) \delta 27.1,69.4,70.1,78.7,80.7$, 114.0, 128.7, 130.0, 130.5, 133.6, 165.7; MS (FAB) $\mathrm{m} / \mathrm{z}$ clacd for $\mathrm{C}_{19} \mathrm{H}_{25} \mathrm{O}_{7} 365.1600$, found $365[\mathrm{M}+\mathrm{H}]^{+}$. 14b : $R_{f} 0.40$ (EtOAc: $n$-Hexane $=1: 2) ; \operatorname{mp~} 206-207{ }^{\circ} \mathrm{C} ;{ }^{1} \mathrm{H} \mathrm{NMR}\left(\mathrm{CDCl}_{3}\right) \delta 1.46(\mathrm{~s}$, $6 \mathrm{H}), 1.49$ (s, 3H), 1.51 (s, 3H), $2.87(\mathrm{~d}, J=4.1 \mathrm{~Hz}, 1 \mathrm{H}, \mathrm{OH}), 3.67-$ 3.95 (m, 4H, H-2, H-3, H-4 \& H-5), 4.13 (ddd, $J=4.1,7.9,10.2$ $\mathrm{Hz}, 1 \mathrm{H}, \mathrm{H}-6), 5.43$ (dd, $J=7.9,10.4 \mathrm{~Hz}, 1 \mathrm{H}, \mathrm{H}-1)$ ) 7.44-8.11 (m, $5 \mathrm{H}, \mathrm{Ph}) ;{ }^{13} \mathrm{C} \mathrm{NMR}\left(\mathrm{CDCl}_{3}\right) \delta 26.9,27.0,27.1,73.0,75.6,75.8$, 76.3, 79.3, 81.7, 114.3, 114.4, 128.8, 129.7, 130.5, 134.0, 167.1; MS (FAB) $m / z$ clacd for $\mathrm{C}_{19} \mathrm{H}_{25} \mathrm{O}_{7} 365.1600$, found $365[\mathrm{M}+\mathrm{H}]^{+}$.

1-O-Benzoyl-4-O-(6- $\mathrm{N}$-Cbz-aminohexanoyl)-2,3:5,6-di$O$-isopropylidine-scyllo-inositol (15): A solution of compound 14a (172 mg, $0.472 \mathrm{mmol}$ ), 6- $\mathrm{N}$-Cbz-aminohexanoic acid (238 $\mathrm{mg}, 0.944 \mathrm{mmol}), \mathrm{EDC}$ (181 $\mathrm{mg}, 0.944 \mathrm{mmol})$ and DMAP (17 $\mathrm{mg}, 0.144 \mathrm{mmol})$ in DMF ( $5 \mathrm{~mL}$ ) was stirred overnight at rt under $\mathrm{N}_{2}$. The reaction mixture was diluted with EtOAc, washed with $\mathrm{H}_{2} \mathrm{O}, \mathrm{NaHCO}_{3}$ and brine. Organic phase was dried and concentrated to give the crude product, which was purified by column chromatography $\left(\mathrm{CH}_{2} \mathrm{Cl}_{2}: \mathrm{MeOH}=35: 1\right)$ to afford compound $15(257 \mathrm{mg}, 89.1 \%)$ as a white solid. $R_{f} 0.29\left(\mathrm{CH}_{2} \mathrm{Cl}_{2}: \mathrm{MeOH}=\right.$ 25:1); mp $217-218{ }^{\circ} \mathrm{C} ;{ }^{1} \mathrm{H} \mathrm{NMR}\left(\mathrm{CDCl}_{3}\right) \delta 1.39-1.45(\mathrm{~m}, 14 \mathrm{H})$, $1.52-1.58(\mathrm{~m}, 2 \mathrm{H}), 1.66-1.75(\mathrm{~m}, 2 \mathrm{H}), 2.42(\mathrm{t}, 2 \mathrm{H}, J=7.31), 3.21$ $(\mathrm{q}, 2 \mathrm{H}, J=6.38 \mathrm{~Hz}), 3.86(\mathrm{~m}, 4 \mathrm{H}), 5.10(\mathrm{~s}, 2 \mathrm{H}), 5.40(\mathrm{t}, 1 \mathrm{H}, J=$ $9.3 \mathrm{~Hz}), 5.59(\mathrm{t}, 1 \mathrm{H}, J=9.26 \mathrm{~Hz}), 7.32-7.38(\mathrm{~m}, 5 \mathrm{H}), 7.44-7.49$ $(\mathrm{m}, 2 \mathrm{H}), 7.56-7.61(\mathrm{~m}, 1 \mathrm{H}), 8.09-8.12(\mathrm{~m}, 2 \mathrm{H}) ;{ }^{13} \mathrm{C} \mathrm{NMR}$ $\left(\mathrm{CDCl}_{3}\right) \delta 25,26.6,27.3,30.2,34.7,41.6,67.3,69.4,70.1,79.1$, 79.1, 114.3, 128.9, 128.8, 129.0, 129.2, 130.3, 130.8, 134.0, 137.3, 157.0, 166.0, 173.0; HRMS (FAB) $m / z$ calcd for $\mathrm{C}_{33} \mathrm{H}_{42}-$ $\mathrm{NO}_{10} 612.2809$, found $612.2808[\mathrm{M}+\mathrm{H}]^{+}$.

1-O-Benzoyl-4-O-(6- $\mathrm{N}$-Cbz-aminohexanoyl)-scyllo-inositol (16): A solution of compound $15(60 \mathrm{mg}, 0.0981 \mathrm{mmol})$ in gaseous $\mathrm{HCl}$ saturated EtOAc $(3 \mathrm{~mL})$ was stirred at rt for $30 \mathrm{~min}$ and evaporated under reduced pressure. The residue was washed several times with ether to afford compound 16 (49.6 g, 95.2\%) as a white solid. mp $193-194{ }^{\circ} \mathrm{C} ;{ }^{1} \mathrm{H} \mathrm{NMR}\left(\mathrm{CD}_{3} \mathrm{OD}\right) \delta 1.38-1.42$ $(\mathrm{m}, 2 \mathrm{H}), 1.48-1.55(\mathrm{~m}, 2 \mathrm{H}), 1.66-1.71(\mathrm{~m}, 2 \mathrm{H}), 2.43(\mathrm{t}, 2 \mathrm{H}, J=$ $7.18 \mathrm{~Hz}), 3.12(\mathrm{t}, 2 \mathrm{H}, J=6.76 \mathrm{~Hz}), 3.50(\mathrm{t}, 2 \mathrm{H}, J=9.55 \mathrm{~Hz}), 3.60$ (t, $2 \mathrm{H}, J=9.50 \mathrm{~Hz}), 4.90-5.12(\mathrm{~m}, 4 \mathrm{H}), 7.27-7.36(\mathrm{~m}, 5 \mathrm{H}), 7.45-$ 
$7.51(\mathrm{~m}, 2 \mathrm{H}), 7.58-7.63(\mathrm{~m}, 1 \mathrm{H}), 8.08-8.10(\mathrm{~m}, 2 \mathrm{H}) ;{ }^{13} \mathrm{C} \mathrm{NMR}$ $\left(\mathrm{CD}_{3} \mathrm{OD}\right) \delta 23.8,25.3,28.7,33.2,39.8,65.4,71.9,71.9,74.5$, 75.4, 126.9, 127.0, 127.5, 127.6, 128.9, 129.7, 132.2, 157.2, 165.9, 173.2; HRMS (FAB) $m / z$ calcd for $\mathrm{C}_{27} \mathrm{H}_{34} \mathrm{NO}_{10} 532.2183$, found $532.2177[\mathrm{M}+\mathrm{H}]^{+}$, calcd for $\mathrm{C}_{27} \mathrm{H}_{33} \mathrm{NO}_{10} \mathrm{Na} 554.2002$, found $554.2040[\mathrm{M}+\mathrm{Na}]^{+}$.

1-O-Benzoyl-4-O-(6- $\mathrm{N}$-Cbz-aminohexanoyl)-2,3,5,6-tetra$O$-[6-[bis-(3- $N, N^{\prime}$-di-Boc-guanidino-propyl)-amino]-hexanoyl]- scyllo-inositol (17a): A solution of compound 16 (20 mg, $0.038 \mathrm{mmol}$ ), 12a (165 mg, $0.23 \mathrm{mmol}), \mathrm{EDC}$ (48.6 mg, 0.23 mmol), and DMAP (7 mg, $0.057 \mathrm{mmol})$ in $\mathrm{CH}_{2} \mathrm{Cl}_{2}(1.5 \mathrm{~mL})$ was stirred at $\mathrm{rt}$ under $\mathrm{N}_{2}$ for $48 \mathrm{~h}$. The reaction mixture was diluted with $\mathrm{CH}_{2} \mathrm{Cl}_{2}$, washed several times with $\mathrm{H}_{2} \mathrm{O}, \mathrm{NaHCO}_{3}$ and brine. The organic phase was dried and concentrated to give the crude product, which was purified on silica gel $\left(\mathrm{CH}_{2} \mathrm{Cl}_{2}\right.$ : $\mathrm{MeOH}=10: 1)$ to afford compound $\mathbf{1 7 a}(109 \mathrm{mg}, 85 \%) ; R_{f} 0.41$ $\left(\mathrm{CH}_{2} \mathrm{Cl}_{2}: \mathrm{MeOH}=10: 1\right) ;{ }^{1} \mathrm{H}$ NMR $\left(\mathrm{CDCl}_{3}\right) \delta$ 0.95-1.96 (m, $178 \mathrm{H}), 1.97-2.04(\mathrm{~m}, 8 \mathrm{H}), 2.05-2.16(\mathrm{~m}, 8 \mathrm{H}), 2.17-2.27(\mathrm{~m}, 8 \mathrm{H})$, $2.28-2.56(\mathrm{~m}, 24 \mathrm{H}), 3.35-3.43(\mathrm{~m}, 16 \mathrm{H}), 5.09(\mathrm{~s}, 2 \mathrm{H}), 5.31-5.53$ $(\mathrm{m}, 6 \mathrm{H}), 7.34-7.35(\mathrm{~m}, 5 \mathrm{H}), 7.39-7.47(\mathrm{~m}, 2 \mathrm{H}), 7.56-7.62(\mathrm{~m}$, 1H), 7.92-7.95 (m, 2H), 8.47 (brs, 8H), 11.48 (brs, $8 \mathrm{H}) ;{ }^{13} \mathrm{C}$ NMR $\left(\mathrm{CDCl}_{3}\right) \delta 24.87,26.07,26.88,27.49,29.80,33.93,34.17$, 39.56, 40.88, 51.54, 54.12, 63.37, 69.71, 70.00, 70.32, 70.47, $79.28,83.06,128.12,128.58,128.83,130.05,153.20,156.22$, 156.64, 163.70, 165.50, 172.06, 173.64; MS (MALDI-TOF) $\mathrm{m} / \mathrm{z}$ calcd for $\mathrm{C}_{163} \mathrm{H}_{277} \mathrm{~N}_{29} \mathrm{O}_{46} 3377.0$, found $3377.1[\mathrm{M}]^{+}$.

1-O-Benzoyl-4-O-(6- $\mathrm{N}$-Cbz-aminohexanoyl)-2,3,5,6-tetra$O$-[8-[bis-(3- $N, N$ '-di-Boc-guanidino-propyl)-amino]-octanoyl]-scyllo-inositol (17b): was similarly prepared from compound 16 (75 mg, $0.14 \mathrm{mmol}), \mathbf{1 2 b}(637.5 \mathrm{mg}, 0.84 \mathrm{mmol})$, EDC (180 $\mathrm{mg}, 0.84 \mathrm{mmol})$, and DMAP (25.8 mg, $0.21 \mathrm{mmol})$. 17b (432.4 $\mathrm{mg}, 88.5 \%): R_{f} 0.46\left(\mathrm{CH}_{2} \mathrm{Cl}_{2}: \mathrm{MeOH}=9: 1\right) ;{ }^{1} \mathrm{H} \mathrm{NMR}\left(\mathrm{CDCl}_{3}\right)$ $\delta$ 0.96-1.95 (m, 194H), 1.96-2.16 (m, 8H), 2.17-2.26 (m, 8H), $2.18-2.57(\mathrm{~m}, 32 \mathrm{H}), 3.32-3.57(\mathrm{~m}, 16 \mathrm{H}), 5.09(\mathrm{~s}, 2 \mathrm{H}), 5.26-5.56$ $(\mathrm{m}, 6 \mathrm{H}), 7.18-7.35(\mathrm{~m}, 5 \mathrm{H}), 7.37-7.50(\mathrm{~m}, 2 \mathrm{H}), 7.52-7.65(\mathrm{~m}$, 1H), 7.88-7.93 (m, 2H), 8.50 (brs, 8H), 11.49 (brs, 8H); ${ }^{13} \mathrm{CNMR}$ $\left(\mathrm{CDCl}_{3}\right) \delta 24.90,26.43,26.73,27.70,29.42,29.51,29.88,33.97$, 34.14, 39.82, 40.96, 51.81, 54.19, 69.76, 70.05, 70.51, 70.54, $79.31,80.03,128.23,128.68,130.10,153.29,156.26,156.61$, 163.83, 165.20, 172.33; MS (MALDI-TOF) $\mathrm{m} / \mathrm{z}$ calcd for $\mathrm{C}_{171^{-}}$ $\mathrm{H}_{293} \mathrm{~N}_{29} \mathrm{O}_{46} 3489.1$, found $3489.3[\mathrm{M}]^{+}$.

1-O-Benzoyl-4-O-(6-aminohexanoyl)-2,3,5,6-tetra- $O$-[6[bis-(3- $N, N^{\prime}$-di-Boc-guanidino-propyl)-amino]-hexanoyl]scyllo-inositol (18a): A mixture of compound 17a (150 mg, $0.0444 \mathrm{mmol})$ in a mixed solvent of $\mathrm{CH}_{2} \mathrm{Cl}_{2}: \mathrm{MeOH}(1: 9,5 \mathrm{~mL})$ was hydrogenated (40 psi) at rt over $10 \% \mathrm{Pd} / \mathrm{C} \mathrm{(30} \mathrm{mg).} \mathrm{After} 24$ $\mathrm{h}$, the catalyst was filtered through celite and the filtrate was evaporated to afford free amine $\mathbf{1 8 a}(141 \mathrm{mg}, 98 \%)$ as an offwhite foamy solid. ${ }^{1} \mathrm{H}$ NMR $\left(\mathrm{CD}_{3} \mathrm{OD}\right) \delta 1.18-1.85(\mathrm{~m}, 166 \mathrm{H})$, $1.88-2.10(\mathrm{~m}, 16 \mathrm{H}), 2.11-2.21(\mathrm{~m}, 4 \mathrm{H}), 2.22-2.42(\mathrm{~m}, 8 \mathrm{H}), 2.75-$ $2.95(\mathrm{~m}, 8 \mathrm{H}), 3.01-3.23(\mathrm{~m}, 24 \mathrm{H}), 3.37-3.51(\mathrm{~m}, 16 \mathrm{H}), 5.48-5.65$ $(\mathrm{m}, 6 \mathrm{H}), 7.50-7.55(\mathrm{~m}, 2 \mathrm{H}), 7.65-7.69(\mathrm{~m}, 1 \mathrm{H})$, 7.95-7.97 (m, $2 \mathrm{H})$.

1-O-Benzoyl-4-O-(6-aminohexanoyl)-2,3,5,6-tetra- $O$-[8[bis-(3- $N, N$ '-di-Boc-guanidino-propyl)-amino]-octanoyl]scyllo-inositol (18b) was similarly prepared. 18b(142 mg, 98\%) as an off-white foamy solid: ${ }^{1} \mathrm{H} \mathrm{NMR}\left(\mathrm{CD}_{3} \mathrm{OD}\right) \delta 1.04-1.82(\mathrm{~m}$, $184 \mathrm{H}), 1.96-2.16(\mathrm{~m}, 24 \mathrm{H}), 2.18-2.42(\mathrm{~m}, 8 \mathrm{H}), 2.98-3.23$ (m,
$28 \mathrm{H}), 3.43-3.58(\mathrm{~m}, 24 \mathrm{H}), 5.41-5.73(\mathrm{~m}, 6 \mathrm{H}), 7.46-7.54(\mathrm{~m}, 2 \mathrm{H})$, 7.60-7.72 (m, 1H), 7.90-8.00 (m, 2H).

1-O-Benzoyl-4- $O$-[6-( $N$-fluoresceinyl-5-thioureido)-hexanoyl]-2,3,5,6-tetra- $O$-[6-[bis-(3- $N, N$ '-di-Boc-guanidino-propyl)-amino]-hexanoyl]-scyllo-inositol (19a): To a solution of 18a (114 mg, $0.035 \mathrm{mmol}$ ) in a mixed solvent THF : abs. ethanol (5 mL, 2:3), were added fluorescein-5-isothiocyanate $(16.4 \mathrm{mg}$, $0.042 \mathrm{mmol})$ and triethylamine $(15 \mu \mathrm{L}, 0.105 \mathrm{mmol})$, and the reaction mixture was stirred for $24 \mathrm{~h}$ at $\mathrm{rt}$ in dark. The reaction mixture was concentrated, diluted with ethyl acetate, and washed with water. Organic phase was dried and concentrated to give the crude product 19a $(130 \mathrm{mg})$ as a yellow sticky glass, which was directly used in the next step. ${ }^{1} \mathrm{H}$ NMR $\left(\mathrm{CDCl}_{3}\right) \delta 1.05-2.95(\mathrm{~m}$, $218 \mathrm{H}), 3.24-3.51(\mathrm{~m}, 24 \mathrm{H}), 5.30-5.65(\mathrm{~m}, 6 \mathrm{H}), 6.50-7.95(\mathrm{~m}$, $14 \mathrm{H}), 8.50$ (brs, $8 \mathrm{H}), 11.42$ (brs, $8 \mathrm{H})$.

1-O-Benzoyl-4- $O$-[6-( $N$-fluoresceinyl-5-thioureido)-hexanoyl]-2,3,5,6-tetra- $O$-[8-[bis-(3- $N, N$ '-di-Boc-guanidino-propyl)-amino]-octanoyl]-scyllo-inositol (19b): was similarly prepared from $18 \mathbf{b}(112 \mathrm{mg}, 0.033 \mathrm{mmol}) . \mathbf{1 9 b}(127 \mathrm{mg})$ as a yellow sticky glass: ${ }^{1} \mathrm{H} \mathrm{NMR}\left(\mathrm{CDCl}_{3}\right) \delta 0.84-2.34(\mathrm{~m}, 216 \mathrm{H}), 2.58-2.93$ $(\mathrm{m}, 24 \mathrm{H}), 3.27-3.56(\mathrm{~m}, 18 \mathrm{H}), 2.58-2.93(\mathrm{~m}, 24 \mathrm{H}), 3.27-3.56$ (m, 18H), 5.22-5.57 (m, 6H), 6.47-7.92 (m, 14H), 8.48 (brs, 8H), 11.42 (brs, $8 \mathrm{H})$.

1-O-Benzoyl-4- $O$-[6-( $N$-fluoresceinyl-5-thioureido)-hexanoyl]-2,3,5,6-tetra- $O$-[6-\{ bis-(3-guanidino-propyl)-amino\}hexanoyl]-scyllo-inositol (2a): A solution of 19a(130 mg crude) in gaseous $\mathrm{HCl}$ saturated ethyl acetate was stirred at $\mathrm{rt}$ for $24 \mathrm{~h}$. The solution was concentrated and repeatedly washed with ethyl acetate and ether, and the crude product was purified by MPLC on Fluka $100 \mathrm{C} 8$-reversed phase silica gel $\left(\mathrm{CH}_{3} \mathrm{CN}\right.$ : $\mathrm{H}_{2} \mathrm{O}=1: 1$, containing $0.1 \%$ TFA in both $\mathrm{CH}_{3} \mathrm{CN}$ and $\mathrm{H}_{2} \mathrm{O}$ ). Upon freeze drying compound $\mathbf{2 a}$ ( $\mathrm{HCl}$-salt) was obtained as a greenish yellow foamy solid (30 mg, 37\% over two steps). UV $\left(\mathrm{H}_{2} \mathrm{O}\right): \lambda_{\max }(\varepsilon)=497 \mathrm{~nm}\left(30416 \mathrm{~cm}^{-1} \mathrm{M}^{-1}\right) ;{ }^{1} \mathrm{H} \mathrm{NMR}\left(\mathrm{CD}_{3} \mathrm{OD}\right)$ $\delta 1.09(\mathrm{~m}, 4 \mathrm{H}), 1.37-1.47(\mathrm{~m}, 12 \mathrm{H}), 1.52-1.58(\mathrm{~m}, 4 \mathrm{H}), 1.59-1.72$ $(\mathrm{m}, 8 \mathrm{H}), 1.73-1.83(\mathrm{~m}, 6 \mathrm{H}), 1.97-2.11(\mathrm{~m}, 18 \mathrm{H}), 2.12-2.24(\mathrm{~m}$, $8 \mathrm{H}), 2.28-2.37(\mathrm{~m}, 6 \mathrm{H}), 2.89-2.97(\mathrm{~m}, 4 \mathrm{H}), 3.18-3.23(\mathrm{~m}, 12 \mathrm{H})$, 3.23-3.37 (m, 16H), 5.53-5.72 (m, 6H), 6.60-6.62 (m, 2H), 6.73$6.77(\mathrm{~m}, 4 \mathrm{H}), 7.21(\mathrm{~m}, 2 \mathrm{H}), 7.53(\mathrm{~m}, 2 \mathrm{H}), 7.68(\mathrm{~m}, 1 \mathrm{H}), 7.73(\mathrm{~m}$, $1 \mathrm{H}), 7.98(\mathrm{~m}, 2 \mathrm{H}) ;{ }^{13} \mathrm{C}$ NMR $\left(\mathrm{CD}_{3} \mathrm{OD}\right) \delta 22.81,23.16,23.75$, 23.96, 25.39, 25.60, 25.72, 29.26, 33.02, 33.19, 38.18, 38.22, 50.26, 50.34, 52.82, 53.07, 70.08, 70.20, 102.21, 112.55, 115.45, $117.77,128.85,128.58,129.02,129.60,153.11,157.46,161.33$, 161.61, 165.05, 171.93, 171.98, 172.31, 181.30; MS (MALDITOF) $m / z$ calcd for $\mathrm{C}_{96} \mathrm{H}_{154} \mathrm{~N}_{30} \mathrm{O}_{17} \mathrm{~S} 2031.2$, found $2031.3[\mathrm{M}]^{+}$; analytical HPLC: $t_{\mathrm{R}}=3.588 \mathrm{~min}$ (flow rate $1 \mathrm{~mL} / \mathrm{min}$; UV: $\lambda=$ $220 \mathrm{~nm} ; \mathrm{H}_{2} \mathrm{O}: \mathrm{CH}_{3} \mathrm{CN}=70: 30$ with $0.1 \%$ TFA), purity $>95 \%$.

1-O-Benzoyl-4- $O$-[6-( $N$-fluoresceinyl-5-thioureido)-hexanoyl]-2,3,5,6-tetra-O-[8-\{ bis-(3-guanidino-propyl)-amino\}octanoyl]-scyllo-inositol (2b) was similarly prepared from $\mathbf{1 9 b}$ (127 mg crude). $\mathbf{2 b}$ (HCl-salt) as a greenish yellow foamy solid (33.3 mg, $41 \%$ over two steps): UV $\left(\mathrm{H}_{2} \mathrm{O}\right): \lambda_{\max }(\varepsilon)=499 \mathrm{~nm}$ $\left(29705 \mathrm{~cm}^{-1} \mathrm{M}^{-1}\right) ;{ }^{1} \mathrm{H}$ NMR $\left(\mathrm{CD}_{3} \mathrm{OD}\right) \delta 1.02-1.09(\mathrm{~m}, 4 \mathrm{H}), 1.10-$ $1.17(\mathrm{~m}, 8 \mathrm{H}), 1.28-1.45(\mathrm{~m}, 24 \mathrm{H}), 1.55-1.58(\mathrm{~m}, 4 \mathrm{H}), 1.62-1.67$ $(\mathrm{m}, 6 \mathrm{H}), 1.68-1.74(\mathrm{~m}, 2 \mathrm{H}), 1.74-1.80(\mathrm{~m}, 4 \mathrm{H}), 2.03-2.09(\mathrm{~m}$, $16 \mathrm{H}), 2.13-2.15(\mathrm{~m}, 4 \mathrm{H}), 2.25-2.29((\mathrm{~m}, 4 \mathrm{H}), 2.31-2.35(\mathrm{~m}, 2 \mathrm{H})$, $3.08-3.13(\mathrm{~m}, 4 \mathrm{H}), 3.16-3.37(\mathrm{~m}, 32 \mathrm{H}), 5.52-5.53(\mathrm{~m}, 3 \mathrm{H}), 5.59-$ $5.63(\mathrm{~m}, 2 \mathrm{H}), 5.67-5.71(\mathrm{~m}, 1 \mathrm{H}), 6.57-6.60(\mathrm{~m}, 2 \mathrm{H}), 6.70-6.74$ 
(m, 4H), 7.19-7.21 (m, 2H), 7.49-7.52 (m, 2H), 7.65-7.68 (m, 1H), 7.72-7.74 (m, 1H), 7.96-7.97 (m, $2 \mathrm{H}) ;{ }^{13} \mathrm{C} \mathrm{NMR}\left(\mathrm{CD}_{3} \mathrm{OD}\right)$ $\delta 22.80,23.16,23.18,23.26,23.40,24.07,24.26,24.43,25.79$, 25.97, 26.07, 28.08, 28.20, 28.30, 28.48, 28.63, 29.26, 33.37, $34.47,38.20,50.27,50.33,53.20,53.27,56.08,69.96,70.10$, $70.30,70.75,102.22,110.17,110.95,112.39,113.35,115.53$, $117.86,120.26,124.37,127.76,128.45,128.88,129.57,133.62$, 152.96, 157.44, 157.46, 161.49, 161.77, 165.16, 169.91, 172.24, $172.25,172.32$; MS (MALDI-TOF) $m / z$ calcd for $\mathrm{C}_{104} \mathrm{H}_{170^{-}}$ $\mathrm{N}_{30} \mathrm{O}_{17} \mathrm{~S} 2143.3$, found $2143.3[\mathrm{M}]^{+}$; analytical HPLC: $t_{\mathrm{R}}=4.958$ $\min$ (flow rate $1 \mathrm{~mL} / \mathrm{min} ; \mathrm{UV}: \lambda=220 \mathrm{~nm} ; \mathrm{H}_{2} \mathrm{O}: \mathrm{CH}_{3} \mathrm{CN}=70: 30$ with $0.1 \%$ TFA), purity $>95 \%$.

1-O-Benzoyl-2-O-(6- $\mathrm{N}$-Cbz-aminohexanoyl)-3,4,5,6-tetraO-benzyl-scyllo-inositol (21): A solution of compound $\mathbf{2 0}^{27}$ (250 $\mathrm{mg}, 0.388 \mathrm{mmol}$ ), 6- $\mathrm{N}$-Cbz-aminohexanoic acid (150 mg, 0.565 $\mathrm{mmol})$, EDC (110 mg, $0.565 \mathrm{mmol}$ ) and DMAP (14 mg, 0.14 $\mathrm{mmol}$ ) in $\mathrm{CH}_{2} \mathrm{Cl}_{2}$ (4 mL) was stirred for $24 \mathrm{~h}$ at rt under $\mathrm{N}_{2}$. The reaction mixture was diluted with $\mathrm{CH}_{2} \mathrm{Cl}_{2}$, washed several times with saturated $\mathrm{NaHCO}_{3}$. The organic phase was dried and concentrated. The residue was purified by column chromatography $($ EtOAc: $n$-Hexane $=1: 3-1: 2)$ to afford compound $14(338 \mathrm{mg}$, $98 \%$ ) as a white sticky solid. $R_{f} 0.45$ (EtOAc: $n$-Hexane $\left.=1: 2\right)$; ${ }^{1} \mathrm{H} \mathrm{NMR}\left(\mathrm{CDCl}_{3}\right) \delta$ 0.91-1.29 (m, 6H), $2.01(\mathrm{t}, J=7.1 \mathrm{~Hz}, 2 \mathrm{H})$, 2.88 (br.s, $2 \mathrm{H}), 3.66-3.70$ (m, 4H), 4.56-4.88 (m, 8H), 5.08 (s, $2 \mathrm{H}), 5.27-5.37(\mathrm{~m}, 2 \mathrm{H}), 7.03-7.53(\mathrm{~m}, 28 \mathrm{H}), 7.94(\mathrm{~d}, J=7.2 \mathrm{~Hz}$, $2 \mathrm{H}) ;{ }^{13} \mathrm{CNMR}\left(\mathrm{CDCl}_{3}\right) \delta 24.2,25.9,29.3,33.8,40.5,66.4,71.7$, $72.6,75.4,75.5,75.9,80.0,80.3,82.6,82.7,127.5,127.62$, $127.65,127.7,127.8,127.9,128.0,128.2,128.3,128.4,128.5$, 129.4, 129.8, 133.3, 136.7, 137.5, 138.1, 138.16, 138.2, 156.2, 165.5, 172.4. HRMS (FAB) $m / z$ calcd for $\mathrm{C}_{55} \mathrm{H}_{58} \mathrm{NO}_{10} 892.4061$, found $892.4069[\mathrm{M}+\mathrm{H}]^{+}$.

1-O-Benzoyl-2-O-(6-aminohexanoyl)-scyllo-inositol (22). A mixture of compound 21 (338 $\mathrm{mg}, 0.379 \mathrm{mmol}$ ) and $20 \mathrm{wt} \%$ $\mathrm{Pd}(\mathrm{OH})_{2} / \mathrm{C}$ (moisture 60\%) (170 mg) in $\mathrm{CH}_{2} \mathrm{Cl}_{2}$ : EtOH (2: 3, $5 \mathrm{~mL}$ ) was hydrogenated under $\mathrm{H}_{2}$ (pressure: $50 \mathrm{psi}$ ) for $48 \mathrm{~h}$. The reaction mixture was filtered through a celite-bed and the filtrate was concentrated to afford compound 22 (140 mg, quantitative $)$ as a white sticky solid. $R_{f} 0.12\left(\mathrm{CH}_{2} \mathrm{Cl}_{2}: \mathrm{MeOH}=5: 1 \times\right.$ $2) ;{ }^{1} \mathrm{H} \mathrm{NMR}\left(\mathrm{CD}_{3} \mathrm{OD}\right) \delta$ 1.09-1.20 (m, 2H), 1.37-1.50 (m, 4H), 2.14-2.35 (m, 2H), $2.67(\mathrm{t}, \mathrm{J}=7.7 \mathrm{~Hz}, 2 \mathrm{H}), 3.38-3.45(\mathrm{~m}, 2 \mathrm{H})$, 3.54-3.67 (m, 2H), 5.12-5.25 (m, 2H), 7.47-7.52 (m, 2H),

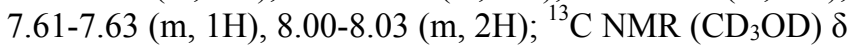
25.3, 26.7, 28.2, 34.8, 40.5, 73.5, 73.7, 74.6, 75.4, 75.5, 129.8, $130.9,131.3,134.7,167.5,174.4$; HRMS (FAB) $m / z$ calcd for $\mathrm{C}_{19} \mathrm{H}_{28} \mathrm{NO}_{8}$ 398.1815, found 398.1816 [M+H] $]^{+}$.

1-O-Benzoyl-2-O-(6- $\mathrm{N}$-Cbz-aminohexanoyl)-scyllo-inositol (23). To a solution of compound $22(130 \mathrm{mg}, 0.352 \mathrm{mmol})$ in 1,4-dioxane: $\mathrm{H}_{2} \mathrm{O}(1: 1,3 \mathrm{~mL})$ at $0{ }^{\circ} \mathrm{C}$ was added triethyl amine $(59 \mu \mathrm{L}, 0.422 \mathrm{mmol}$ ), and the solution was stirred for $5 \mathrm{~min}$. Benzyl chloroformate $(98 \mu \mathrm{L}, 0.7 \mathrm{mmol})$ was added to the reaction mixture and the solution stirred for overnight at rt. The reaction mixture was evaporated to dryness, diluted with EtOAc and washed with water and brine solution. The organic phase was dried and concentrated. The crude residue was purified by flash chromatography $\left(\mathrm{CH}_{2} \mathrm{Cl}_{2}: \mathrm{MeOH}=12: 1\right)$ to afford compound 23 (120 mg, 68\%) as a white solid. $R_{f} 0.28\left(\mathrm{CH}_{2} \mathrm{Cl}_{2}: \mathrm{MeOH}=10: 1\right)$; $\mathrm{mp}=105-106{ }^{\circ} \mathrm{C} ;{ }^{1} \mathrm{H} \mathrm{NMR}\left(\mathrm{CD}_{3} \mathrm{OD}\right) \delta 1.04-1.36(\mathrm{~m}, 6 \mathrm{H}), 2,14-$ 2.23 (m, 2H), 2.86-2.89 (m, 2H), 3.38-3.41 (m, 2H), 3.52-3.62 $(\mathrm{m}, 2 \mathrm{H}), 5.05(\mathrm{~s}, 2 \mathrm{H}), 5.10-5.20(\mathrm{~m}, 2 \mathrm{H}), 7.35-7.57(\mathrm{~m}, 8 \mathrm{H})$, 7.99-8.01 (m, 2H); ${ }^{13} \mathrm{C} \mathrm{NMR}\left(\mathrm{CD}_{3} \mathrm{OD}\right) \delta 25.6,27.2,30.5,35.1$, 41.6, 67.4, 73.6, 73.7, 74.5, 75.4, 75.6, 128.9, 129.1, 129.6, 129.7, 131.0, 131.3, 134.6, 138.6, 158.9, 167.5, 174.7; HRMS (FAB) $m / z$ calcd for $\mathrm{C}_{27} \mathrm{H}_{34} \mathrm{NO}_{10} 532.2183$, found 532.2180 $[\mathrm{M}+\mathrm{H}]^{+}$.

1-O-Benzoyl-2-O-(6- $\mathrm{N}-\mathrm{Cbz}$-aminohexanoyl)-3,4,5,6-tetra$O$-[6-[bis-(3- $N, N$ '-di-Boc-guanidino-propyl)-amino]-hexanoyl]-scyllo-inositol (24). A solution of compound 23 (30 mg, $0.059 \mathrm{mmol})$, linker 12a (261 mg, $0.357 \mathrm{mmol})$, EDC (68 mg, $0.357 \mathrm{mmol})$ and DMAP ( $8.7 \mathrm{mg}, 0.071 \mathrm{mmol})$ in dry DMF (2 $\mathrm{mL}$ ) was stirred for $48 \mathrm{~h}$ at $\mathrm{rt}$ under $\mathrm{N}_{2}$. The reaction mixture was diluted with EtOAc, washed several times with saturated $\mathrm{NaHCO}_{3}$. The organic phase was dried and concentrated. The residue was purified by column chromatography $\left(\mathrm{CH}_{2} \mathrm{Cl}_{2}\right.$ : $\mathrm{MeOH}=10: 1)$ to afford compound $\mathbf{2 4}(185 \mathrm{mg}, 92 \%)$ as a white foamy solid. $R_{f} 0.36\left(\mathrm{CH}_{2} \mathrm{Cl}_{2}: \mathrm{MeOH}=10: 1\right) ;{ }^{1} \mathrm{H} \mathrm{NMR}\left(\mathrm{CDCl}_{3}\right)$ $\delta$ 0.91-1.69 (m, 190H), 2.10-2.46 (m, 32H), 2.90-2.95 (m, 4H), $3.38-4.22(\mathrm{~m}, 16 \mathrm{H}), 4.88-5.51(\mathrm{~m}, 6 \mathrm{H}), 5.07\left(\mathrm{~s}, 2 \mathrm{H}, \mathrm{CH}_{2} \mathrm{Ph}\right)$ 7.30-7.36 (m, 5H), 7.39-7.45 (m, 2H), 7.54-7.60 (m, 1H), 7.917.95 (m, 2H), 8.49 (brs, 8H), 11.49 (brs, 8H); ${ }^{13} \mathrm{C} \mathrm{NMR}\left(\mathrm{CD}_{3} \mathrm{OD}\right)$ $\delta 24.3,24.8,24.9,26.0,26.3,26.9,27.2,27.5,27.8,28.1,28.4$, 28.6, 29.4, 29.7, 33.7, 34.0, 34.1, 34.2, 39.6, 40.6, 51.5, 51.7, 53.1, 53.6, 53.8, 63.3, 66.5, 69.2, 69.6, 69.8, 69.9, 70.1, 70.4, 77.4, 79.1, 82.9, 128.1, 128.5, 128.7, 129.9, 133.9, 136.8, 153.1, 156.1, 156.4, 162.5, 163.7, 165.0, 171.8, 171.9, 172.0, 173.6, 174.1; MS (MALDI-TOF) $\mathrm{m} / z$ calcd for $\mathrm{C}_{163} \mathrm{H}_{281} \mathrm{~N}_{29} \mathrm{O}_{46}$ 3381.0541, found $3381.0720[\mathrm{M}+4 \mathrm{H}]^{+}$.

1-O-Benzoyl-2-O-(6-aminohexanoyl)-3,4,5,6-tetra- $O$-[6[bis-(3- $N, N$ '-di-Boc-guanidino-propyl)-amino]-hexanoyl]scyllo-inositol (25). A mixture of compound 24 (100 mg, 0.03 mmol) in a mixed solvent of $\mathrm{CH}_{2} \mathrm{Cl}_{2}: \mathrm{MeOH}(1: 9,5 \mathrm{~mL})$ was hydrogenated (40 psi) over 10\% Pd/C (25 mg) at rt. After $24 \mathrm{~h}$, the catalyst was filtered through a celite bed and the filtrate was evaporated to afford free amine $\mathbf{2 5}$ (96 $\mathrm{mg}, 99 \%)$ as a sticky solid. ${ }^{1} \mathrm{H} \mathrm{NMR}\left(\mathrm{CDCl}_{3}\right) \delta 1.06-2.26(\mathrm{~m}, 202 \mathrm{H}), 2.88-3.70(\mathrm{~m}, 40 \mathrm{H})$, 5.31-5.56 (m, 6H), 7.45-7.50 (m, 2H), 7.61-7.64 (m, 1H), 7.93$7.95(\mathrm{~m}, 2 \mathrm{H}), 8.47$ (s, 8H), 11.43 (m, 8H); MS (MALDI-TOF) $m / z$ calcd for $\mathrm{C}_{155} \mathrm{H}_{273} \mathrm{~N}_{29} \mathrm{O}_{44}: 3245.0016$, found 3245.1240 $[\mathrm{M}+2 \mathrm{H}]^{+}$.

1-O-Benzoyl-2-O-[6-( $\mathrm{N}$-fluoresceinyl-5-thioureido)-hexanoyl]-3,4,5,6-tetra- $O$-[6-[bis-(3- $N, N^{\prime}$-di-Boc-guanidino-propyl)-amino]-hexanoyl]-scyllo-inositol (26). To a solution of 25 $(88 \mathrm{mg}, 0.027 \mathrm{mmol})$ in a mixed solvent THF:abs. ethanol (5 $\mathrm{mL}, 2: 3)$, were added fluorescein-5-isothiocyanate $(12.7 \mathrm{mg}$, $0.032 \mathrm{mmol})$ and triethylamine $(11.3 \mu \mathrm{L}, 0.081 \mathrm{mmol})$. The reaction mixture was stirred for $24 \mathrm{~h}$ at $\mathrm{rt}$ in dark, concentrated, diluted with ethyl acetate, and washed with water. Organic phase was dried and concentrated. The crude product $\mathbf{2 6}(99 \mathrm{mg})$ was used in the next reaction without further purification. ${ }^{1} \mathrm{H}$ NMR $\left(\mathrm{CDCl}_{3}\right) \delta 1.02-2.88(\mathrm{~m}, 226 \mathrm{H}), 3.32-3.51(\mathrm{~m}, 16 \mathrm{H}), 3.62-4.12$ $(\mathrm{m}, 2 \mathrm{H}), 5.05-5.61(\mathrm{~m}, 6 \mathrm{H}), 6.56-7.90(\mathrm{~m}, 14 \mathrm{H}), 8.50$ (brs, $8 \mathrm{H})$, 11.44 (brs, 8H).

1-O-Benzoyl-2- $O$-[6-( $N$-fluoresceinyl-5-thioureido)-hexanoyl]-3,4,5,6-tetra-O-[6-\{ bis-(3-guanidino-propyl)-amino\}hexanoyl]-scyllo-inositol (3a). A solution of 26 (99 $\mathrm{mg})$ in gaseous $\mathrm{HCl}$ saturated ethyl acetate was stirred at rt for $24 \mathrm{~h}$, concentrated and repeatedly washed with ethyl acetate and ether 
to give the crude product, which was purified by MPLC on Fluka $100 \mathrm{C} 8$-reversed phase siica gel $\left(\mathrm{CH}_{3} \mathrm{CN}: \mathrm{H}_{2} \mathrm{O}=1: 1\right.$, containing $0.1 \%$ TFA in both $\mathrm{CH}_{3} \mathrm{CN}$ and $\mathrm{H}_{2} \mathrm{O}$ ). Upon freeze drying compound 3a (as $\mathrm{HCl}$ salt) was obtained as a greenish yellow foamy solid (41.2 mg, $73 \%$ over two steps): $\mathrm{UV}\left(\mathrm{H}_{2} \mathrm{O}\right): \lambda_{\max }(\varepsilon)=$ $497 \mathrm{~nm}\left(48139 \mathrm{~cm}^{-1} \mathrm{M}^{-1}\right) ;{ }^{1} \mathrm{H}$ NMR $\left(\mathrm{CD}_{3} \mathrm{OD}\right) \delta 1.15-2.38(\mathrm{~m}$, $80 \mathrm{H}), 2.88-3.66(\mathrm{~m}, 16 \mathrm{H}), 5.56-5.72(\mathrm{~m}, 6 \mathrm{H}), 7.20-7.70(\mathrm{~m}$, $10 \mathrm{H}), 7.91-8.59(\mathrm{~m}, 4 \mathrm{H})$; MS (MALDI-TOF) $\mathrm{m} / \mathrm{z}$ calcd for $\mathrm{C}_{96^{-}}$ $\mathrm{H}_{155} \mathrm{~N}_{30} \mathrm{O}_{17} \mathrm{~S} 2032.2$, found $2032.2[\mathrm{M}+\mathrm{H}]^{+}$; analytical HPLC: $t_{\mathrm{R}}=4.699 \mathrm{~min}$ (flow rate $1 \mathrm{~mL} / \mathrm{min} ; \mathrm{UV}: \lambda=254 \mathrm{~nm} ; \mathrm{H}_{2} 0$ : $\mathrm{CH}_{3} \mathrm{CN} 70$ : 30 with $0.1 \%$ TFA), purity $>95 \%$.

\section{Bioassays.}

Cell culture: Human cervical cancer-derived HeLa cells were cultured in Dulbecco's Modified Eagle's Medium (DMEM, Gibco) supplemented with $10 \%$ (v/v) newborn calf serum (Gibco), $100 \mathrm{units} / \mathrm{mL}$ of penicillin, $100 \mu \mathrm{g} / \mathrm{mL}$ of streptomycin and $0.25 \mu \mathrm{g} / \mathrm{mL}$ of amphotercin B (Gifco) in an incubator at $37{ }^{\circ} \mathrm{C}$, under an atmosphere containing air and $5 \% \mathrm{CO}_{2}$.

Imaging analysis: The cells $\left(1.0 \times 10^{4} /\right.$ well $)$ were seeded into 96-well plate, cultured overnight and treated with compounds at the indicated concentration in the presence of $250 \mathrm{nM}$ MitoTracker Deep Red (Molecular Probes) for $10 \mathrm{~min}$. After washing with serum-free DMEM, images were captured by Image Xpress and analyzed by MetaXpress (Molecular Devices inc.).

Cellular uptake experiment: The cells $\left(5.0 \times 10^{5}\right)$ were seeded into $60 \mathrm{~mm}$ dish, cultured overnight and treated with compounds at the indicated concentration for $10 \mathrm{~min}$. The cells were washed in basal DMEM, and incubated for $30 \mathrm{~min}$. After trypsinization, the cells were harvested, centrifuged and resuspended in PBS, and the fluorescence was measured via flow cytometry. Treatment with DMSO only as a negative control and 500 nM MitoTracker Deep Red or MitoTracker Green FM (Molecular Probes) was used as a positive control, respectively. Data represent uptake percent for 10,000 cells per sample.

Tissue distribution study: Each transporter $[1 \mathbf{a}(84.5 \mathrm{mg}$ $\left.\mathrm{kg}^{-1}\right), \mathbf{1 b}\left(88.6 \mathrm{mg} \mathrm{kg}^{-1}\right), \mathbf{2 a}\left(84.5 \mathrm{mg} \mathrm{kg}^{-1}\right), \mathbf{2 b}\left(85.0 \mathrm{mg} \mathrm{kg}^{-1}\right), \mathbf{3 a}$ $\left(84.5 \mathrm{mg} \mathrm{kg}^{-1}\right)$,] was dissolved in sterile distilled water $(1 \mathrm{~mL})$ and injected into 8-week-old mice (C57BL/6) intraperitoneally. The treated mice were perfused after 20 minutes with $4 \%$ para- formaldehyde in PBS (pH 7.4). The organs were incubated overnight in $0.5 \mathrm{M}$ sucrose in PBS. Placed in cryoprotectant, they were cut into $15-\mu \mathrm{m}$ sections with cryostat, and transferred to coated glass slides. After drying at $37{ }^{\circ} \mathrm{C}$, the sections were washed with PBS and treated with $0.3 \%$ Triton X-100 for 15 minutes at room temperature and analyzed with an Axioplan2 fluorescence imaging microscope.

\section{Results and Discussion}

All transporters used in the present studies (1-3) were prepared from the myo-inositol derivative $\mathbf{6},{ }^{26}$ essentially according to the reported procedures. ${ }^{14-17}$ For the synthesis of transporter $\mathbf{1}$, the $\mathrm{C} 1-\mathrm{OH}$ of compound $\mathbf{6}$ was condensed with $N$-Cbz protected 6-aminohexanoic acid using 1-(3-dimethylaminopropyl)-3ethylcarbodiimide (EDC) and 4-dimethylaminopyridine (DMAP), and then the acetonide protecting groups were removed by treatment with EtOAc saturated with $\mathrm{HCl}$ (g) to provide compound $\mathbf{8}$. Exhaustive coupling of $\mathbf{8}$ with bisguanidinylated carboxylic acid 12a and $\mathbf{1 2} b^{15}$ in the presence of EDC and DMAP gave the acylated products in good yields. Removal of the $N-\mathrm{Cbz}$ protecting group in the side chain of the acylated products by hydrogenolysis, attachment of the fluorescent probe on the primary amino group with fluorescein-5-isothiocyanate (FITC-I), and finally removal of the Boc groups on the guanidine groups in EtOAc saturated with $\mathrm{HCl}(\mathrm{g})$ gave desired MTs $\mathbf{1 a}$ and $\mathbf{1 b}$ (Scheme 1). The scyllo-inositol based transporters $\mathbf{2}$ and 3a were similarly prepared from 13, 20 and requisite components respectively (Scheme 2 and 3). The transporters (1-3) obtained as their $\mathrm{HCl}$ salt were rigorously purified by medium-pressure liquid chromatography (MPLC) on a reverse phase (C8) silica gel column, and preparative high performance liquid chromatography (HPLC) on a reverse phase (C18) column when necessary. They were all satisfactorily characterized by ${ }^{1} \mathrm{H}$ NMR spectroscopy and MALDI-TOF mass spectral analyses. The sample purity was assessed by analytical HPLC on a ZORBAX SB-C8 reverse phase column $(5 \mu \mathrm{m}, 4.6 \mathrm{~mm}$ ID $\times 25 \mathrm{~cm}$; flow rate $1 \mathrm{~mL}$ $\min ^{-1}$ of $\mathrm{CH}_{3} \mathrm{CN}: \mathrm{H}_{2} \mathrm{O}=30: 70$ with $0.1 \%$ TFA; detection $\mathrm{UV}$ at $\lambda=220 \mathrm{~nm}$ ). The molecular transporters showed the following

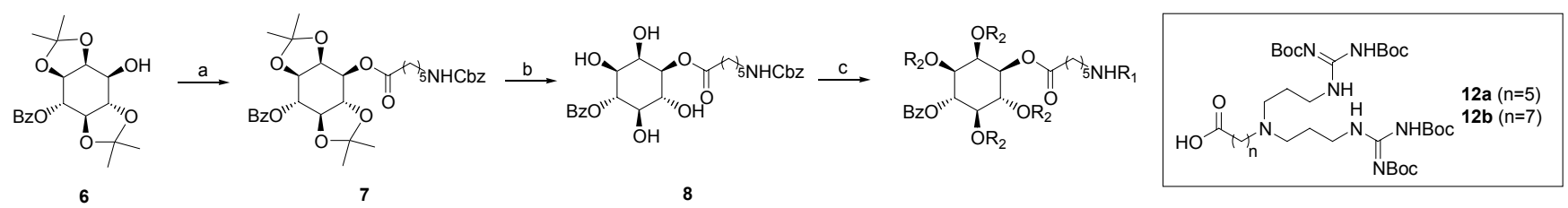

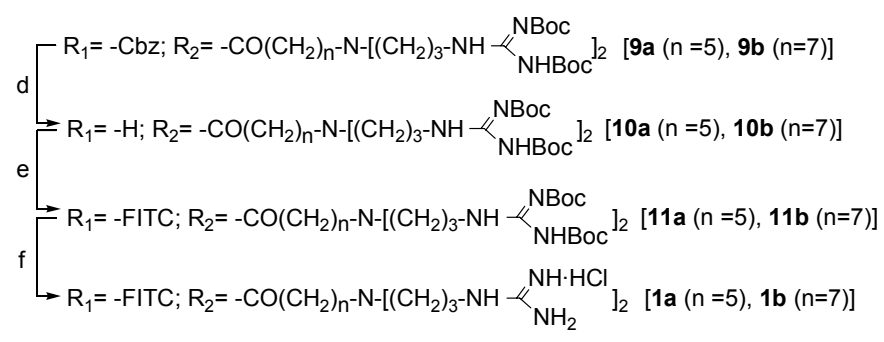

Scheme 1. a. $\mathrm{HO}_{2} \mathrm{C}\left(\mathrm{CH}_{2}\right)_{5}$-NHCbz, EDC, DMAP, DMF, 12 h, RT, 86\%; b. HCl (g), EtOAc, DCM, MeOH, 0.5 h, RT, $91 \%$; c. 12a or 12b, EDC, DMAP, DMF, 48 h, 92\% \& 95\%; d. 10\% Pd/C, $\mathrm{H}_{2}$ (50 psi), DCM, MeOH, 24 h, RT, 98\%; e. FITC-I, TEA, THF, EtOH, 24 h, RT; f. HCl (g), EtOAc, $24 \mathrm{~h}, \mathrm{RT}, 40 \%$ \& $42 \%$ over two steps 
<smiles>OC1[C@H](O)[C@H](O)[C@@H](O)[C@H](O)[C@H]1O</smiles>

13

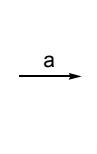<smiles>CC(C)(C)OC1C(O)C2OC(C)(C)OC2C(O)C1OC(C)(C)C</smiles>

$14 a$<smiles>CC(C)(C)OC1C([OH2+])C(O)C(O)C2OC(C)(C)OC21</smiles>

14b

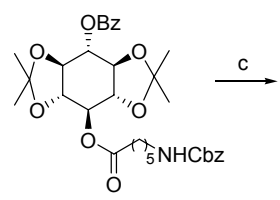

15

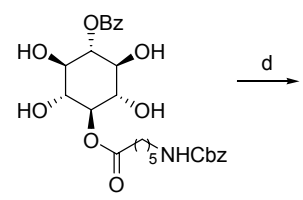

16

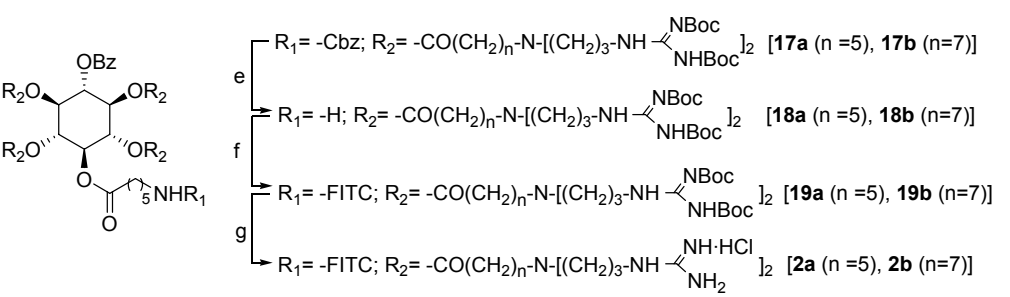

Scheme 2. a. 2-methoxypropene, $p$-TSA, DMF, 24 h, rt, $22.8 \%$ (14a) \& $11.5 \%$ (14b); b. $\mathrm{HO}_{2} \mathrm{C}\left(\mathrm{CH}_{2}\right)_{5} \mathrm{NHCbz}$, EDC, DMAP, DCM, 24 h, rt, $89 \%$; c. $\mathrm{HCl}$ (g), EtOAc, 0.5 h, rt, 95\%; d. 12a or 12b, EDC, DMAP, DCM, 48h, rt, $85 \%$ (17a) \& $88 \%$ (17b); e. $10 \% \mathrm{Pd} / \mathrm{C}, \mathrm{H}_{2}(50 \mathrm{psi}), \mathrm{DCM}, \mathrm{MeOH}$, 24 h, rt, 98\%; f. FITC-I, TEA, EtOH, THF, 24 h, rt; g. HCl (g), EtOAc, rt, 24 h, 37 - 41\% over two steps

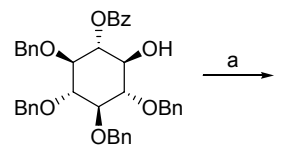

20

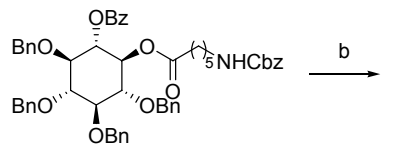

21

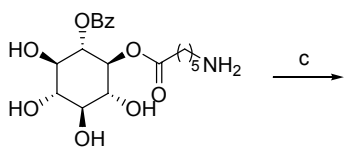

22

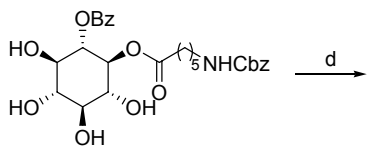

23

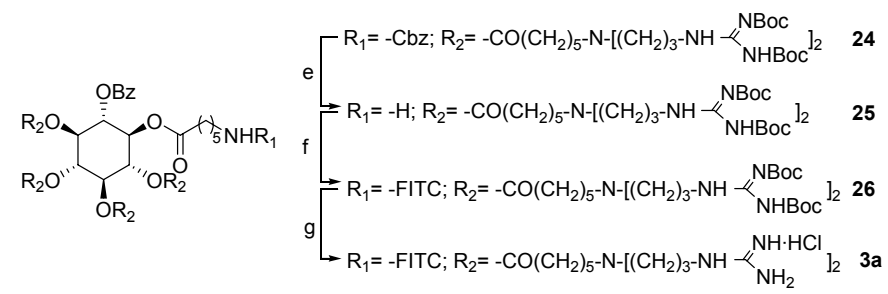

Scheme 3. a. $\mathrm{HO}_{2} \mathrm{C}\left(\mathrm{CH}_{2}\right)_{5} \mathrm{NHCbz}$, EDC, DMAP, DCM, 24 h, rt, 98\%; b. 20\% Pd(OH) $/$ /C, $\mathrm{H}_{2}(50$ psi), DCM, EtOH, 24 h, rt, quant.; c. CbzCl, TEA, 1,4-dioxane, $\mathrm{H}_{2} \mathrm{O}$, rt , 68\%; d. 12a, EDC, DMAP, DCM, 48 h, rt, 92\%; e. 10\% Pd/C, $\mathrm{H}_{2}$ (50 psi), DCM, MeOH, 24 h, rt, $99 \%$; f. FITC-I, TEA, EtOH, THF, rt, 24 h; g. $\mathrm{HCl}$ (g), EtOAc, 24 h, rt, 73\% over two steps

retention times on the C8 column: $\mathbf{1 a}, 3.254 ; \mathbf{1 b}, 3.910 ; \mathbf{2 a}$, $3.617 ; \mathbf{2 b}, 4.690 ; \mathbf{3 a}, 3.754 \mathrm{~min}$.

First, the cellular uptake property of compounds 1-3 was examined in live HeLa cells by confocal laser scanning microscopy (CLSM) with FITC-labeled arginine octamer (R8-F1) as the reference. After incubation with $5.0 \mu \mathrm{M}$ of each transporter for $10 \mathrm{~min}$ at $37^{\circ} \mathrm{C}$, the cells were found substantially marked with the green fluorescence. The quantitative uptake efficiencies were measured by fluorescence-activated cell-sorter (FACS) for all five transporters, and the results are summarized in Fig. 1. The FACS analyses show that all MTs are internalized substantially better than R8-F1. The MTs with longer linker chains (1b and 2b) show more efficient uptake than the shorter chain versions (1a and 2a) as expected, and the MT with the ortholike substitution (3a) shows better uptake than the one with para-like substitution (2a). The intracellular localization patterns of all MTs $(2.5-5.0 \mu \mathrm{M})$ were examined without fixing in HeLa cells by co-incubating with MitoTracker Red (500 nM,
Invitrogen) at $37{ }^{\circ} \mathrm{C}$ for $10 \mathrm{~min}$, and the results are shown in Fig. 2. The myo-inositol based transporters (1a and $\mathbf{1 b})$ showed good localization in mitochondria (Fig. 2a), whereas the scylloinositol based transporters (2a, 2b, and 3a) displayed little affinity toward mitochondria showing only punctate patterns with poorly defined localization. (Fig. 2b). Previously, with the lactose- and sucrose-based transporters the lipophilicity reflected in the HPLC retention time on a reverse phase column, ${ }^{28-30}$ appeared to be somewhat correlated to the mitochondrial affinity. ${ }^{16,17}$ However, the present cases show poor correlation between the HPLC-based lipophilicity and the mitochondrial localization. Instead the mitochondrial affinity appears better correlated with the stereochemistry of the scaffold; transporters 1a and $\mathbf{1 b}$ (myo-inositol, para-like substitution) show good affinity toward mitochondria, whereas transporters $\mathbf{2} \mathbf{a}$ and $\mathbf{2 b}$ with identical structures except the scaffold stereochemistry (scylloinositol, para-like), and 3a (scyllo-inositol, ortho-like) do not exhibit much affinity for mitochondria. 
(a)

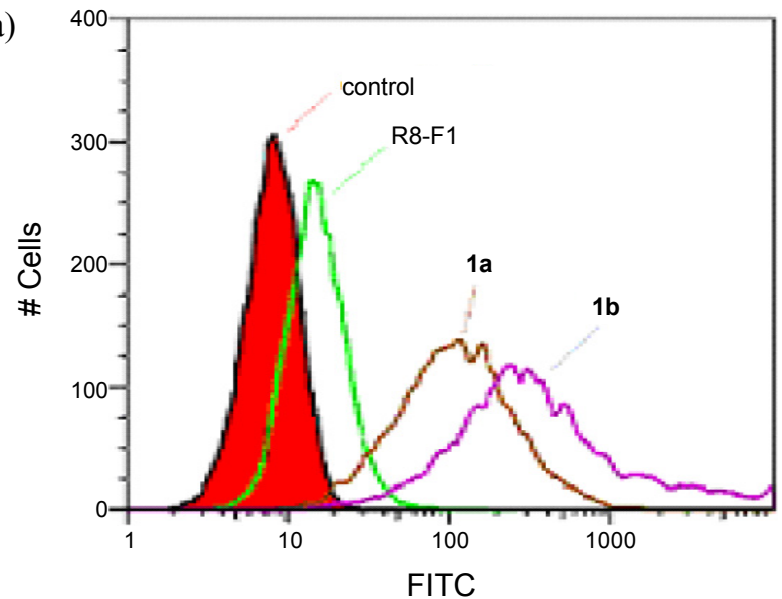

(b)

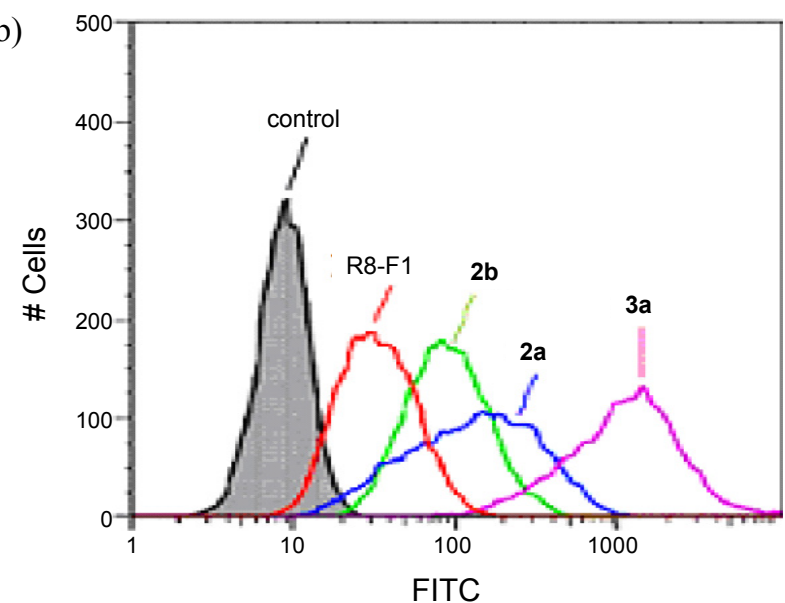

Figure 1. Cellular uptake studies of molecular transporters $\mathbf{1 a}, \mathbf{1 b}, \mathbf{2 a}, \mathbf{2 b}$, and $\mathbf{3 a}(5.0 \mu \mathrm{M}$ each) by flow cytometry. The HeLa cells were incubated with compounds or only DMSO (as control) in serum-containing DMEM at $37^{\circ} \mathrm{C}$ for $10 \mathrm{~min}$ and analyzed for their average fluorescence intensity.

(a)
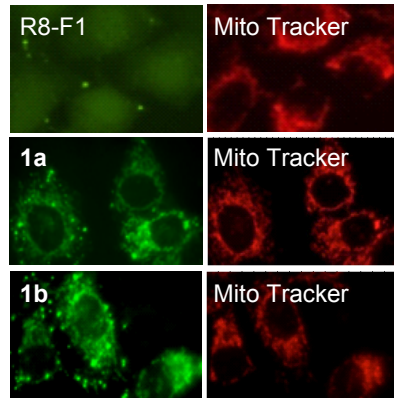
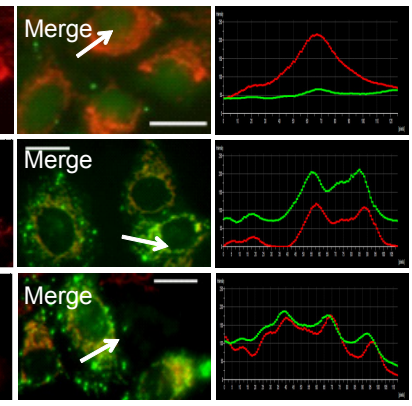

(b)

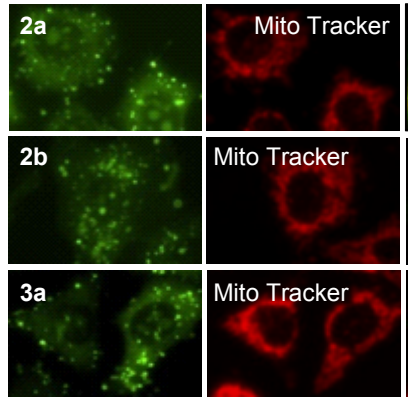

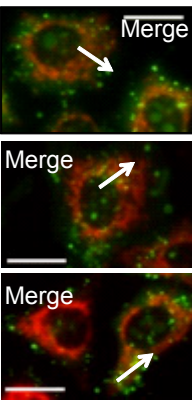

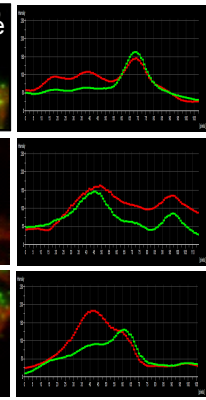

Figure 2. Mitochondrial localization studies of transporters. a) Fluorescence microscope images of compound 1a, and $\mathbf{1 b}$ and their localization in mitochondria. HeLa cells were treated with $1 \mathbf{a}(2.5 \mu \mathrm{M})$, and $\mathbf{1 b}(2.5 \mu \mathrm{M})$ and with MitoTracker Red $(500 \mathrm{nM})$ at $37^{\circ} \mathrm{C}$ for 10 min, with significant localization in mitochondria. b) Little colocalization from $2 \mathrm{a}(5.0 \mu \mathrm{M}), \mathbf{2 b}(5.0 \mu \mathrm{M})$, and $\mathbf{3 a}(5.0 \mu \mathrm{M})$ with MitoTracker Red $(500 \mathrm{nM})$ is seen. Intensity profiles for localization were analyzed for each arrow in the merged image. Scale bars: $20 \mu \mathrm{M}$.

The mouse tissue distribution patterns of the transporters were examined. Each transporter $\left[\mathbf{1 a}\left(84.5 \mathrm{mg} \mathrm{kg}^{-1}\right), \mathbf{1 b}(88.6 \mathrm{mg}\right.$ $\left.\left.\mathrm{kg}^{-1}\right), \mathbf{2 a}\left(84.5 \mathrm{mg} \mathrm{kg}^{-1}\right), \mathbf{2} \mathbf{b}\left(85.0 \mathrm{mg} \mathrm{kg}^{-1}\right), \mathbf{3 a}\left(84.5 \mathrm{mg} \mathrm{kg}^{-1}\right)\right]$ was dissolved in sterile distilled water and injected intraperitoneally ( $i p$ ) into 8-week-old mice (C57BL/6). After 20 min, the treated mice were perfused with $4 \%$ paraformaldehyde in phosphate buffered saline solution (PBS; $\mathrm{pH}$ 7.4), and the major organs (heart, spleen, liver, kidneys, lungs, and brain) were incubated overnight in a solution of $0.5 \mathrm{M}$ sucrose in PBS. Placed in cryoprotectant, they were cut into $15-\mu \mathrm{m}$ sections with a cryostat and transferred to coated glass slides. After drying at $37^{\circ} \mathrm{C}$, the sections were washed with PBS and treated with $0.3 \%$ Triton X-100 for $15 \mathrm{~min}$ at rt, and analyzed with an Axioplan2 fluorescence imaging microscope (Fig. 3). Some selectivity trends in the tissue distribution are observed: 1) all transporters show a good affinity for brain; 2) myo-inositol based transporters $(\mathbf{1} \mathbf{a}, \mathbf{1 b})$ show an affinity toward liver and spleen to a degree; 3) scyllo-inositol based transporters $(\mathbf{2 a}, \mathbf{2 b}, \mathbf{3 a})$ are much widely distributed in all organs including kidney, lung, heart, spleen and liver. It is clear that all transporters can overcome the mouse blood-brain-barrier (BBB), when given via either the ip or per oral ( $p o$ ) route (Fig. 1 in Supplementary Materials).

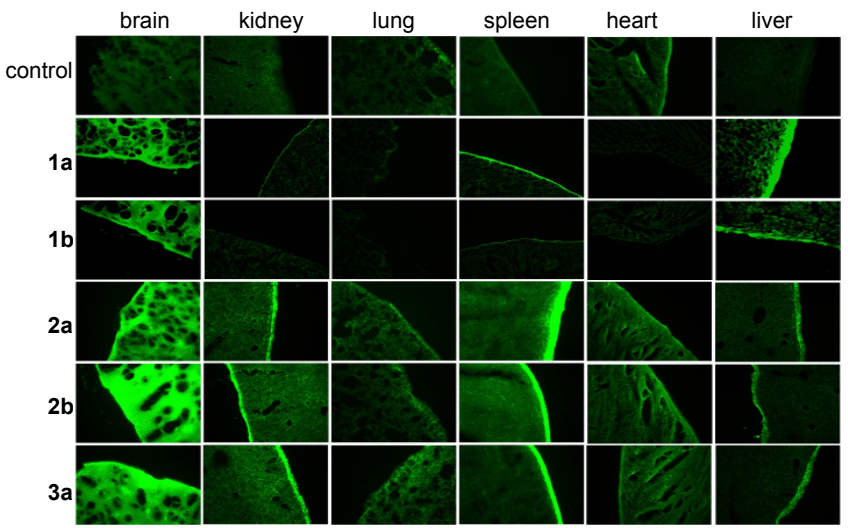

Figure 3. Distribution patterns of molecular transporters in mouse tissues by ip injection. Exposure times (ms): brain-10000, kidney-2500, lung-5000, spleen-1000, heart-1000, liver-2500. $\lambda_{\max }=488 \mathrm{~nm}$ (green fluorescence from FITC).

\section{Conclusion}

In summary, we have prepared five G8 molecular transporters built on two stereoisomeric inositol (myo- and scyllo-) scaffolds, 
and examined their cellular uptake properties and the intracellular localization patterns. Transporters $\mathbf{1 a}$ and $\mathbf{1 b}$ (myo-inositol scaffold with para-like substitution) were found to target mitochondria, whereas transporters, $\mathbf{2} \mathbf{a}$ and $\mathbf{2 b}$ (scyllo-inositol, para-like), and 3a (scyllo-inositol, ortho-like) did not show much affinity for mitochondria. Although the mitochondrial affinity of guanidine-rich MTs generally appears to result from the subtle interplay of the number of charge (guanidine residues), geometric factors (scaffold and linker chain), and the overall lipophilicity, the present study demonstrates importance of the stereochemistry of the scaffold as a key parameter. ${ }^{32}$

Acknowledgments. Financial Support from BK21 and National Frontier Research Program of Korean MOEST (administered via $\mathrm{KRICT/CBM)} \mathrm{is} \mathrm{gratefully} \mathrm{acknowledged.}$

\section{References}

1. Langel, Ü. Handbook of Cell-Penetrating Peptides, 2nd ed.; CRC Press: Boca Raton, 2006

2. Wender, P. A.; Galliher, W. C.; Goun, E. A.; Jones, L. R.; Pillow, T. H. Adv. Drug Deliv. Rev. 2008, 60, 452-472.

3. Nakase, I.; Takeuchi, T.; Tanaka, G.; Futaki, S. Adv. Drug Deliv. Rev. 2008, 60, 598-607.

4. Jolit, A.; Prochiantz, A. Nature Cell Biol. 2004, 6, 189-196.

5. Chung, S. K.; Maiti, K. K.; Lee, W. S. Int. J. Pharmaceutics 2008 , $354,16-21$

6. Wender, P. A.; Mitchell, D. J.; Pattabiraman, K.; Pelkey, E. T.; Steinman, L.; Rothbard, J. B. Proc. Nat. Acad. Sci. USA 2000, 97, 13003-13008.

7. Wender, P. A.; Rothbard, J. B.; Jessop, T. C.; Kreider, E. L.; Wylie, B. L. J. Am. Chem. Soc. 2002, 124, 13382-13383.

8. Umezawa, N.; Gelman, M. A.; Haigis, M. C.; Raines, R. T.; Gellman, S. H. J. Am. Chem. Soc. 2002, 124, 368-369.

9. Rueping, N.; Mahajan, Y.; Sauer, M.; Seebach, D. Chem BioChem 2002, 257-259.

10. Zhou, P.; Wang, M.; Du, L.; Fisher, G. W.; Waggoner, A.; Ly, D. H. J. Am. Chem. Soc. 2003, 125, 6878-6879.

11. Luedtke, N. W.; Carmichael, P.; Tor, Y.J. Am. Chem. Soc. 2003, $125,12374-12375$.
12. Fernandez-Carneado, J.; Van Gool, M.; Martos, V.; Castel, S.; Prados, P.; de Mendoza, J.; Giralt, E. J. Am. Chem. Soc. 2005, 127, 869-874.

13. Chung, H. H.; Harms, G.; Seong, C. M.; Choi, B. H.; Min, C.; Taulane, J. P.; Goodman, M. Biopolymers 2004, 76, 83-96.

14. Maiti, K. K.; Jeon, O. Y.; Lee, W. S.; Kim, D. C.; Kim, K. T.; Takeuchi, T.; Futaki, S.; Chung, S. K. Angew. Chem. Int. Ed. 2006, 45, 2907-2912.

15. Maiti, K. K.; Lee, W. S.; Takeuchi, T.; Watkins, C.; Fretz, M.; Kim, D. C.; Futaki, S.; Jones, A.; Kim, K. T.; Chung, S. K. Angew. Chem. Int. Ed. 2007, 46, 5880-5884.

16. Biswas, G.; Jeon, O. Y.; Lee, W. S.; Lee, S.; Chang, S.; Kim, D. C.; Kim, K. T.; Chung, S. K. Chem. Eur. J. 2008, 14, 9161-9168.

17. Lee, W. S.; Im, C. N.; Teng, Q. Y.; Chang, Y. T.; Kim, D. C.; Kim, K. T.; Chung, S. K. Mol. Biosyst. 2009, 5, 822-825.

18. Weissig, V.; Cheng, S. M.; D’Souza, G. G. M. Mitochondrion 2004, 3, 229-244.

19. Hoye, A. T.; Davoren, J. E.; Wipf, P.; Fink, M. P.; Kagan, V. E. Acc. Chem. Res. 2008, 41, 87-97.

20. Yamada, Y.; Harashima, H. Adv. Drug Deliv. Rev. 2008, 60, 14391462.

21. Wallace, D. C. Science 1999, 283, 1482-1488.

22. Green, D. R.; Reed, J. C. Science 1998, 281, 1309-1312.

23. Dawson, V. L. Nat. Med. 2004, 10, 905-906.

24. Bae, B. I.; Igarashi, S.; Fujimori, M.; Argrawal, N.; Taya, Y.; Hayward, S. D.; Moran, T. H.; Ross, C. A.; Snyder, S. H.; Sawa, A. Neuron 2005, 47, 29-41.

25. Manczak, M.; Anekonda, T. S.; Henson, E.; Park, B. S.; Quinn, J.; Reddy, P. M. Hum. Mol. Genet. 2006, 15, 1437-1449.

26. Khersonskt, S. M.; Chang, Y. T. Carbohydr. Res. 2002, 337, 75-78.

27. Chung, S. K.; Kwon, Y. U.; Chang, Y. T.; Sohn, K. H.; Shin, J. H.; Hong, B. J.; Chung, I. H. Bioorg. Med. Chem. 1999, 7, 2577-2589.

28. Haky, J. E.; Young, A. M. J. Liq. Chromatogr. 1984, 7, 675-689.

29. Lombardo, F.; Shalaeva, M. Y.; Tupper, K. A.; Gao, F.; Abraham, M. H. J. Med. Chem. 2000, 43, 2922-2928.

30. Lombardo, F.; Shalaeva, M.; Tupper, K. A.; Gao, F. J. Med. Chem. 2001, 44, 2490-2497.

31. All mouse experiments were performed in the POSTECH animal facility in compliance with the relevant laws and institutional guidelines.

32. Lee, W. S.; Kim, W.; Kim, K. T.; Chung, S. K. manuscript in preparation. 